\title{
A comprehensive study of Al-Cu-Mg system reinforced with nano-ZrO2 particles synthesized by powder metallurgy technique
}

\section{Waheed S. AbuShanab}

Marine Engineering Department, Faculty of Maritime Studies and Marine Engineering, King Abdulaziz University, Jeddah 21589, Saudi Arabia

\section{Essam B. Moustafa}

Mechanical Engineering Departments, Faculty of Engineering, King Abdulaziz University, Jeddah 21589,

Saudi Arabia

\section{E. Ghandourah}

Department of Nuclear Engineering, Faculty of Engineering, King Abdulaziz University, Jeddah 21589, Saudi Arabia

\section{Mohammed Taha ( $D$ mtahanrc@gmail.com )}

Solid State Physics Department, National Research Centre, El Buhouth St., Dokki, 12622 Giza, Egypt

\section{Research Article}

Keywords: Al matrix nanocomposite, Powder metallurgy, CTE, strength, Wear rate, Yonge's modulus

Posted Date: March 19th, 2021

DOl: https://doi.org/10.21203/rs.3.rs-326782/v1

License: (c) (i) This work is licensed under a Creative Commons Attribution 4.0 International License. Read Full License 


\title{
A comprehensive study of Al-Cu-Mg system reinforced with nano- $\mathrm{ZrO}_{2}$ particles synthesized by powder metallurgy technique
}

\author{
Waheed S. AbuShanab a , Essam B. Moustafa ${ }^{\text {b }}$, E. Ghandourah ${ }^{\mathrm{c}}$,
} Mohammed A. Taha ${ }^{\mathrm{d}, *}$

${ }^{a}$ Marine Engineering Department, Faculty of Maritime Studies and Marine

Engineering, King Abdulaziz University, Jeddah 21589, Saudi Arabia

${ }^{b}$ Mechanical Engineering Departments, Faculty of Engineering, King Abdulaziz

University, Jeddah 21589, Saudi Arabia

${ }^{c}$ Department of Nuclear Engineering, Faculty of Engineering, King Abdulaziz

University, Jeddah 21589, Saudi Arabia

${ }^{d}$ Solid State Physics Department, National Research Centre, El Buhouth St., Dokki, 12622 Giza, Egypt.

\section{Corresponding author}

Mohammed A. Taha*

mtahanrc@gmail.com

\begin{abstract}
Recently, increasing attention has been devoted to improving the various properties of aluminum alloys such as strength, elastic modulus, and coefficient of thermal expansion (CTE) as well as wear and corrosion by adding different percentages of ceramics for use in various industrial applications. In this sense, powder metallurgy technique has been used to fabricate $\mathrm{Al}-4.2$ wt.\% $\mathrm{Cu}-1.6$ wt.\% $\mathrm{Mg}$ matrix nanocomposites reinforced by different weight percentages of nano- $\mathrm{ZrO}_{2}$ particles. The microstructure and particle size distributions of the prepared powders were examined by SEM, TEM technique and diffraction particle size analyzer. The prepared powders were compacted and sintered in argon to obtain good


sinterability. The physical, elastic and mechanical properties of the sintered nanocomposites were measured. Furthermore, thermal expansion, wear and corrosion behavior were also studied. The results showed that the decrease in the particle sizes of the $\mathrm{Al}-\mathrm{Cu}-\mathrm{Mg}$ alloy by adding $\mathrm{ZrO}_{2}$ nanoparticles up to $47.8 \mathrm{~nm}$ for the composite containing 16 wt.\% $\mathrm{ZrO}_{2}$. With increasing the sintering temperature to $570{ }^{\circ} \mathrm{C}$, the densification of nanocomposites was clearly enhanced. Also, the coefficient of thermal expansion and wear rate were remarkably decreases about 28 and $37.5 \%$ with adding after adding $16 \mathrm{wt} . \% \mathrm{ZrO}_{2}$. Moreover, microhardness yield, strength and Young's modulus were enhanced to 161, 145 and $64 \%$, respectively after adding $16 \mathrm{wt} . \% \mathrm{ZrO}_{2}$. In addition, increasing the exposure time was responsible for decreasing the corrosion rate for the same sample.

\section{Key words}

Al matrix nanocomposite; Powder metallurgy; CTE; strength; Wear rate; Yonge's modulus.

\section{Introduction}

In recent years, technological progress has required unique properties such as high strength, high corrosion resistance, better fatigue strength and high wear resistance, etc., which cannot be achieved in metals alone. In this context, researchers have considered manufacturing metal-based composites. Aluminum is the best preferred material as a matrix for the production of $\mathrm{Al}$ matrix compounds (AMCs) reinforced with ceramic particles. Due to these attractive properties, AMCs have a strong role to play in different industrial areas such as car enterprises, aerospace, defense and military industries [1-3]. On the other hand, Al 
alloys are best used as a matrix due to their high strength and low ductility compared to pure Al.

Noteworthy, several articles [4-6] attributed the high resistance of Al and its alloys against corrosion in air to their ability to form an oxide layer that protects them from the attack of corrosive solutions. In order to further improve their corrosion resistance, some corrosion inhibitors can be added to modify the neighboring environment. Notably, these corrosion inhibitors include alloying elements, anodizing the surface, and/or painting their surfaces with a protective coating layer [7,8]. In spite of these amazing properties, other monolithic alloys are more desirable than AMCs where the latter nanocomposites possess several drawbacks such as manufacturing defects, internal stress, differences in microstructure and coupling of the matrix and reinforcement which consequently, leads to galvanic effects [9]. There are several studies investigating the properties of $\mathrm{Al}$ and $\mathrm{Al}$ alloy matrix composites. For example, Zulfia et al. [10] a stir casting method was used to produce $\mathrm{Al}$ alloy reinforced with $\mathrm{SiC}$ particles. The results showed a clear improvement in the tensile strength of the composite by adding 8 vol.\% of SiC particles. Canakci et al. [11] studied the effect of B4C weight percentages mechanical properties of $\mathrm{Al}-\mathrm{Cu}-\mathrm{Mg}$ alloy. It was clearly observed that the milling time caused a homogenous distribution of $\mathrm{B} 4 \mathrm{C}$ nanoparticles in the $\mathrm{Al}$ $\mathrm{Cu}-\mathrm{Mg}$ alloy matrix. Furthermore, a clear improvement in mechanical properties was by adding B4C nanoparticles.

Importantly, the addition of ceramics like $\mathrm{SiC}$ [3,12], $\mathrm{Al}_{2} \mathrm{O}_{3}$ [13], $\mathrm{ZrO}_{2}$ [14], TiC [15] and graphene [16,17] is considered as the optimal solution to overcome this serious obstacle. In this sense, fine stabilized $\mathrm{ZrO}_{2}$ is a good choice for this required task due to its superior mechanical properties, high melting temperature, better corrosion resistance, compared to that of $\mathrm{Al}$ and its alloys, and perfect thermal and chemical stability [10]. Under the effect of its particle size, the 
interaction of particles with dislocations easily occurs which consequently, gives a great significance on the enhancement of densification of the sintered samples and consequently, the improvement of wear, corrosion resistance and mechanical properties [18]. It is substantial to underline that there are many effective routes for the production of $\mathrm{Al}$ and its alloy matrix nanocomposites such as fraction stir [19], squeeze casting [20], stir casting [21] and mechanical alloying (MA) [22,23]. The latter one is a modern cost-effective tool for good dispersion of reinforcement in a metal matrix giving uniform particle distribution in the microstructure [24,25]. Notably, there are various types of ball mill, which are necessary for MA, to perform the required fracture and welding process for powder particles bearing in mind that MA process is highly dependent upon the main parameters like milling time, speed, mill type, ball-to-powder (BPR) ratio and vial/ball material which consequently, control the size as well as shape of the produced reinforcing material [25-27]. Based on the abovementioned advantages of MA, this process is able to fabricate various MMCs with the desirable properties [28].

In previous researches, the effect of different ceramics on some properties of $\mathrm{Al}$ alloys has been studied, and this is the reason for restricting the use of $\mathrm{Al}$ alloys in many industries. Based on these facts, the main objective of the current research is to improve the mechanical, and elastic properties and coefficient of thermal expansion along with its resistance to wear and corrosion through adding different percentages of nano- $\mathrm{ZrO}_{2}$ particles up to $16 \mathrm{wt} . \%$.

\section{Materials and experimental set up}

In this work, we selected an $\mathrm{Al}-4.2 \mathrm{Cu}-1.6 \mathrm{Mg}$ aluminum alloy as a matrix, and nano- $\mathrm{ZrO}_{2}(<50 \mathrm{~nm})$ particles used as reinforced with various weight percentages up to $16 \mathrm{wt} . \%$. To prepare the $\mathrm{Al}-4.2 \mathrm{Cu}-1.6 \mathrm{Mg}$ alloy, the following commercial 
materials have been used: Al (99.9 wt. \%), copper (99.9 wt. \%), and magnesium (99.95 wt.\%). The components of Al alloy have been blended with a planetary ball mill for $20 \mathrm{~h}$ with rotation speed=120 rpm. In order to obtain nanocomposites, the nano- $\mathrm{ZrO}_{2}$ was added with different weight percentages to the $\mathrm{Al}-10 \mathrm{Si}-0.6 \mathrm{Mg}$ alloy shown in Table 1. Subsequently, these mixtures were subjected to the a milling process for $20 \mathrm{~h}$ with rotation speed $=500 \mathrm{rpm}$ having in mind that the milling process was done in a cycle of $2 \mathrm{~h}$ and paused for $2 \mathrm{~h}$.

Table 1. The composition of the prepared samples.

\begin{tabular}{ccc}
\hline Sample & \multicolumn{2}{c}{ The composition (wt. \%) } \\
\hline & $\mathrm{Al}-\mathrm{Cu}-\mathrm{Mg}$ alloy & $\mathrm{ZrO}_{2}$ \\
\cline { 2 - 3 } $\mathrm{AZ0}$ & 100 & 0 \\
$\mathrm{AZ2}$ & 98 & 2 \\
$\mathrm{AZ4}$ & 96 & 4 \\
$\mathrm{AZ8}$ & 92 & 8 \\
$\mathrm{~A} 16$ & 84 & 16 \\
\hline
\end{tabular}

In order to investigate the morphology of the mechanically alloyed powders were characterized using transmission electron microscopy (TEM, type JEOL JEM1230). Moreover, particle size was measured using Diffraction Particle Size Analyzer to get the average distribution pattern for each powder was employed. Then, the milled powders were pressed and sintered at 470 and $570{ }^{\circ} \mathrm{C}$ in an argon atmosphere for $1 \mathrm{~h}$. Notably, the rule of mixture was carried out to calculate the theoretical densities of samples taking into account the density of the $\mathrm{Al}-\mathrm{Cu}-\mathrm{Mg}$ alloy $=2.7 \mathrm{~g} / \mathrm{cm}^{3}$ and the density of $\mathrm{ZrO}_{2}=5.68 \mathrm{~g} / \mathrm{cm}^{3}$. On the other hand, 
Archimedes method was carried out to measure both bulk density and apparent porosity. The microstructure of the powder and sintered samples was investigated by scanning electron microscopy (SEM; Philips XL30). Moreover, using (Netzsch DIL402 PC; Germany), thermal expansion of specimens was measured in the range from 30 to $400{ }^{\circ} \mathrm{C}$. Vickers microhardness (Hv) was measured with a Shimadzu-HMV (Japan) according to ASTM: B933-09 as described in Ref. [29]. Furthermore, the compressive tests of the sintered nanocomposites were performed according to ASTM E9-19 standard. The ultimate strength, yield strength, and elongation were calculated from stress-strain curve; hence the ultimate strength and elongation are the maximum values of stress and strain on stress-strain curve, respectively. On the other hand, yield strength was calculated using the $0.2 \%$ offset principle. Using the pulse-echo technique (MATEC Model MBS8000 DSP) system, the longitudinal and shear velocities of the ultrasonic wave were obtained at room temperature to obtain Lame's constants as indicated from Ref. [30]. The wear test was carried out using pin-on-disk tester machine, the specimens were weighed and measured by a digital balance of accuracy of $0.0001 \mathrm{~g}$. All samples were prepared with same dimensions and polished well by using set of grinding papers with different grades from (600 to 4000). The test was carried out using four different loads. The wear rate due to the weight loss was calculated from the following equations (Eq. 8 and 9) [31]:

Net weight $=$ weight before wear - weight after wear

Wear rate $=$ net weight $/$ time

The corrosion rate of the sintered samples was determined using static immersion weight loss method at room temperature where each sample was weighed before its immersion in $1 \mathrm{M}$ HCL solution and later taken out after 24, 48, 72, 96, 120 and 144 h. After drying thoroughly, the specimens were weighted again. The weight 
loss was measured and converted into corrosion rate expressed in $\mathrm{mm}$ penetration per year $(\mathrm{mm} / \mathrm{year})$.

\section{Results and discussion}

\subsection{Milled powders}

Fig. 1 illustrates the microstructure of $\mathrm{Al}$ alloy and its composites powders with different $\mathrm{ZrO}_{2}$ contents after milled $20 \mathrm{~h}$. The most likely explanation of such observations is that during mechanical milling, the particles of $\mathrm{Al}$ alloy matrix are subjected to deformation (flatting), while $\mathrm{ZrO}_{2}$ particles are subjected to fragmentation. When the particles of $\mathrm{Al}$ alloy matrix (ductile particles) start to weld, $\mathrm{ZrO}_{2}$ particles come between two or more matrix particles at the moment of ball collision. As a result, $\mathrm{ZrO}_{2}$ particles reside at the interfacial boundaries of the welded matrix particles, and the result is the formation of real nanocomposite powders [28]. It is interesting to note that these decreases in particles sizes due to an increasing of local plastic deformation in the vicinity of $\mathrm{ZrO}_{2}$ particles. Moreover, $\mathrm{ZrO}_{2}$ particles act as milling balls and can cause higher energy transfer to $\mathrm{Al}$ alloy matrix. On the other hand, with increasing of $\mathrm{ZrO}_{2}$ contents, fracturecold welding mechanism quickly occurs $[10,11]$. TEM micrographs of as-received $\mathrm{ZrO}_{2}$ nanoparticles along with those of the $\mathrm{Al}$ alloy containing 0,8 and $16 \mathrm{wt} . \%$ $\mathrm{ZrO}_{2}$ after milling are illustrated in Fig. 2 (a-d). As can be seen from Fig. 1a, $\mathrm{ZrO}_{2}$ particles are little of agglomeration, located in the nano-scale range and their sizes do not exceed $50 \mathrm{~nm}$. It is obvious from the figure that increasing of $\mathrm{ZrO}_{2}$ content is responsible for considerable small decrease in particles agglomeration. Due to a high degree of agglomeration, as seen from Fig. 2, particles sizes are difficult to measure. That is why we measure the particle size distribution.

The particle size distribution of the milled powders samples at various weight percent of nano- $\mathrm{ZrO}_{2}$ particle as shown in Fig.3. As the $\mathrm{ZrO}_{2}$ content 
increased, the particle size decreased and shifted distribution to smaller sizes. The mean particles sizes of AZ0, AZ2, AZ4, AZ8 and AZ16 samples were 94.8, 87.7, $74.3,61.2$ and $47.8 \mathrm{~nm}$, respectively.
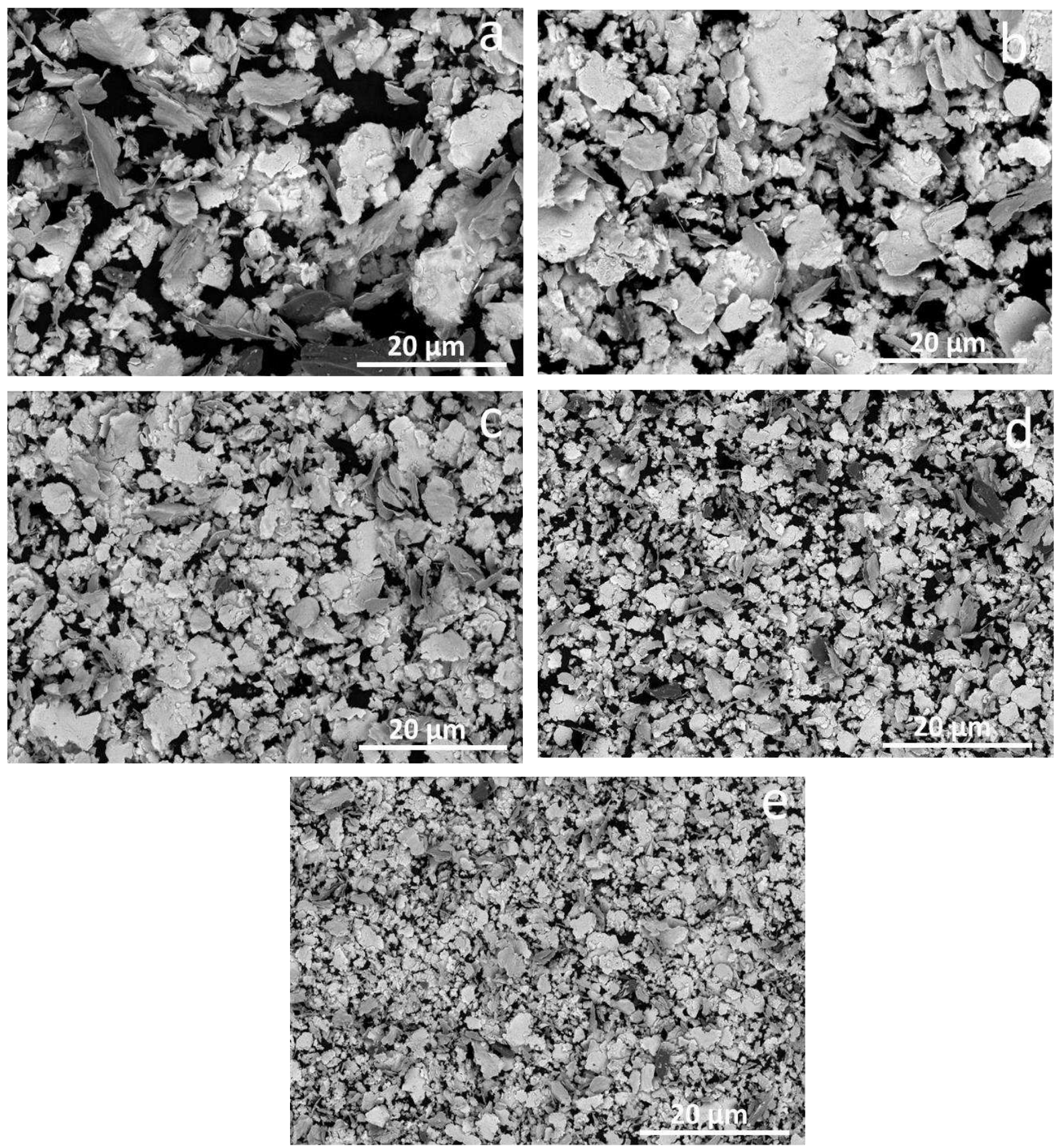

Fig.1 SEM micrographs of milled powders (a) AZ0, (b) AZ2, (c) AZ4, (d) AZ4 and(e) AZ16 samples. 

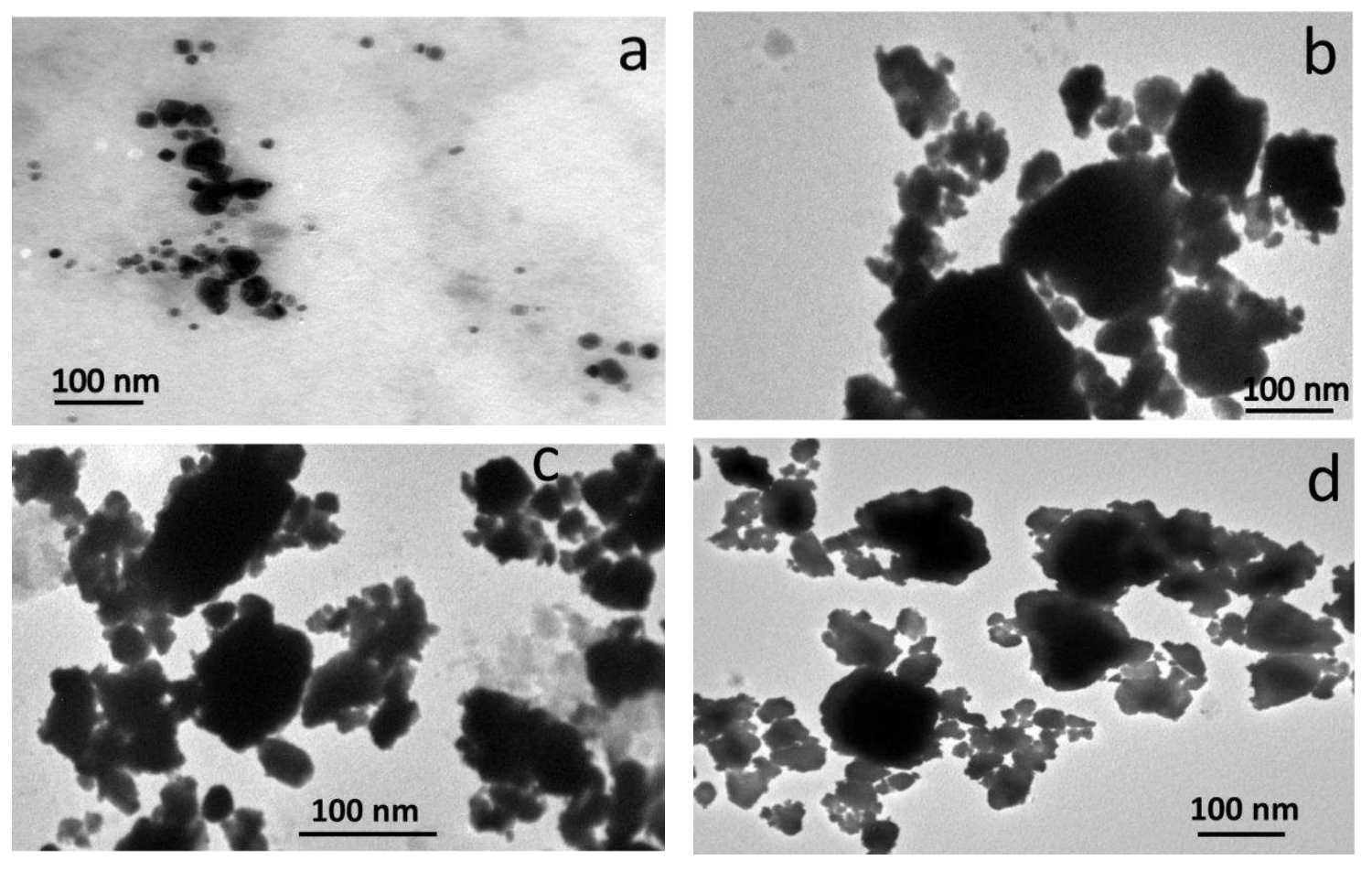

Fig.2 TEM micrographs of (a) as-received $\mathrm{ZrO}_{2}$ nanoparticles, (b) AZ0, (c) AZ8 and (d) AZ16 samples. 

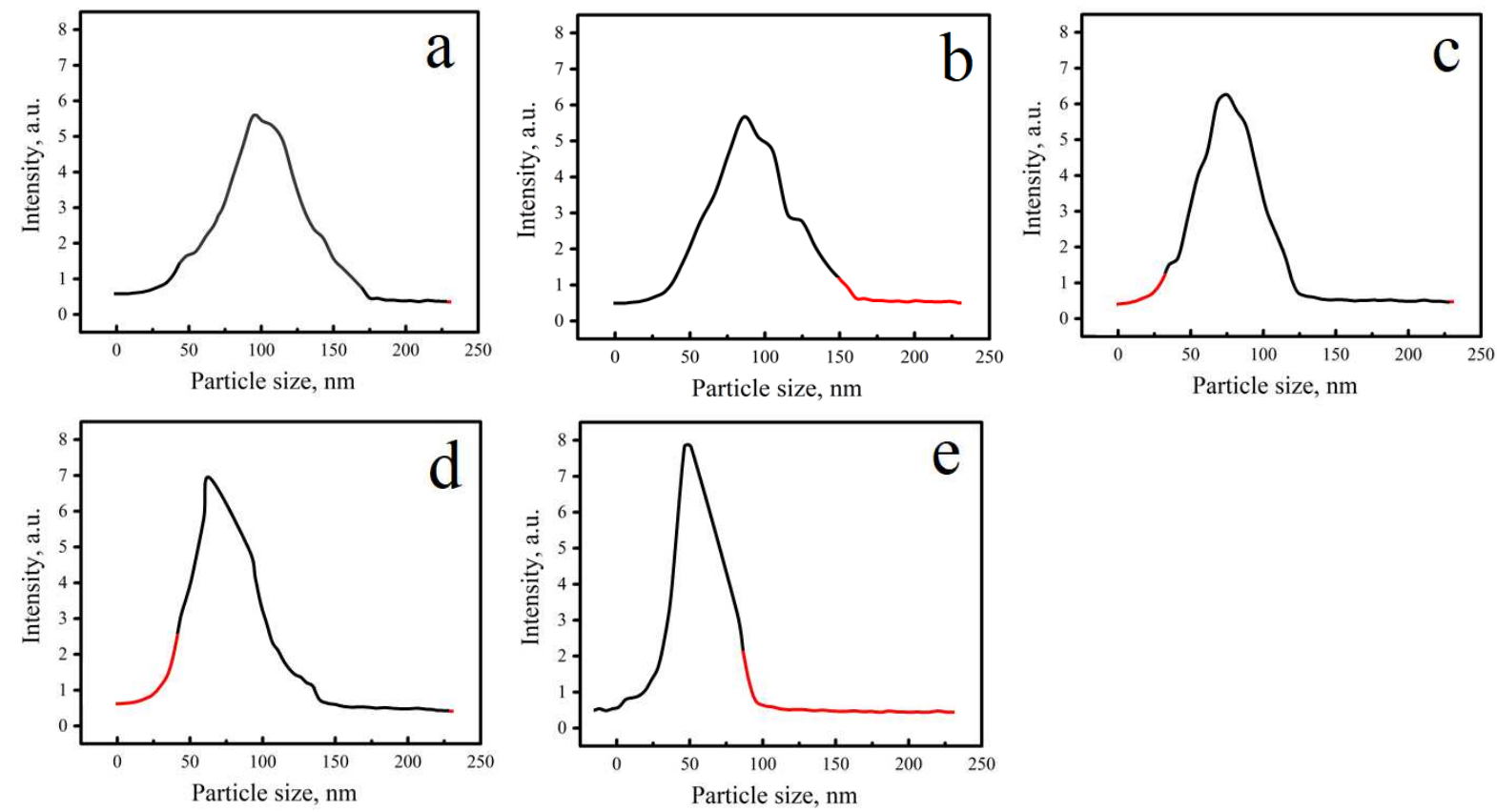

Fig. 3. Particle size distribution of milled powders at various $\mathrm{ZrO}_{2}$ content

\subsection{Sintered nanocomposites}

\subsubsection{Physical properties}

The compaction of the milled nanocomposites powders is an important step for getting bulk materials after mechanical alloying process. Therefore, this step not only controls the porosity but also the shape of the final sintered nanocomposites [32]. Bar graph that explains relative density and apparent porosity of the sintered samples for $1 \mathrm{~h}$ at 470 and $570{ }^{\circ} \mathrm{C}$ as a function of $\mathrm{ZrO}_{2}$ weight percentages is represented in Fig. 4. By considering the theoretical densities of AZ0, AZ2, AZ4, AZ8 and AZ16 samples=2.65, 2.68, 2.71, 2.77 and $2.90 \mathrm{~g} / \mathrm{cm}^{3}$, respectively, the values of the relative densities of AZ0 and AZ16 after sintering at $460{ }^{\circ} \mathrm{C}$ are 93.22 and $85.96 \%$, respectively. On the opposite side, those of the apparent porosity are 6.88 and $11.01 \%$, respectively for the same samples sintered 
at $460{ }^{\circ} \mathrm{C}$. This result may be due to that increasing of $\mathrm{ZrO}_{2}$ weight percentages, in the $\mathrm{Al}$ alloy matrix, leads to a reduction in the pressing capacity of the sintered samples because of higher hardness of $\mathrm{ZrO}_{2}$ ceramic particles. Moreover, the melting point of $\mathrm{ZrO}_{2}$ reinforcement $\left(\approx 2715{ }^{\circ} \mathrm{C}\right)$ is much more than that of $\mathrm{Al}$ matrix and hence, increased $\mathrm{ZrO}_{2}$ contents has an inhibitor effect for the sintering process and consequently, acts as a barrier against diffusion steps during this process [33]. On the contrary, increasing of sintering temperature from 470 to 570 ${ }^{\circ} \mathrm{C}$ has an effective role for the improvement of relative density due to the formation of necks between particles and bonding between particles increase [34]. Moreover, increased sintering temperatures lead to the acceleration of solid-state diffusion and consequently, better densification behavior [35]. When sintering temperature $=570{ }^{\circ} \mathrm{C}$, the relative density of samples decreases from 97.56 to 92.11\% by increasing of $\mathrm{ZrO}_{2}$ contents from 0 to 16 wt. $\%$.
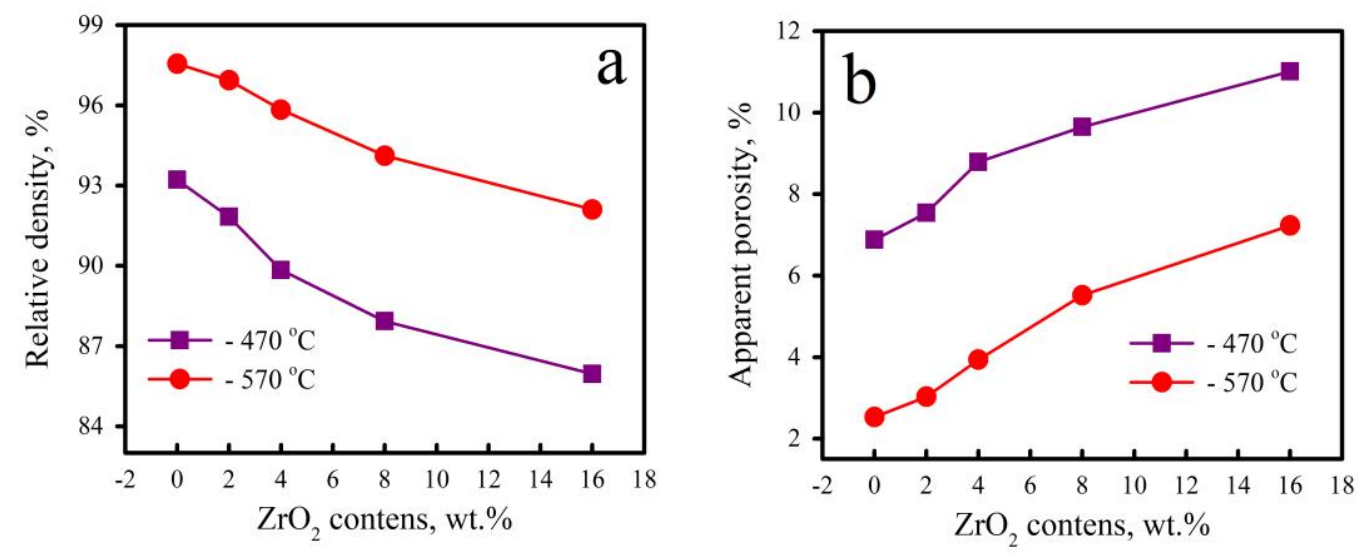

Fig.4. (a) Relative density and (b) apparent porosity of the prepared nanocomposites samples sintered

\subsubsection{Microstructure}

SEM micrographs of the compacted AZ0, AZ4 and AZ16 nanocomposites powders, after $20 \mathrm{~h}$ of milling and compressing at $50 \mathrm{MPa}$, are shown in Fig. 5 (a- 
c). Careful analyses of SEM micrographs reveal the distribution of nano- $\mathrm{ZrO}_{2}$ particles in Al alloy matrix with good densification manner has a strong role to play in both mechanical and electrical properties of the final nanocomposites. Figs. 6 and 7 illustrate the SEM images of nanocomposites with different nano- $\mathrm{ZrO}_{2}$ contents and sintered at 470 and $570{ }^{\circ} \mathrm{C}$ along with their corresponding EDS patterns. Generally, at lower sintering temperature, i.e. $470{ }^{\circ} \mathrm{C}$, nano- $\mathrm{ZrO}_{2}$ particles are found at the grain borders of Al alloy matrix considering the sample has the lowest $\mathrm{ZrO}_{2}$ content, exhibits homogenous distribution for $\mathrm{ZrO}_{2}$ particles noting that this good distribution decreases with increased $\mathrm{ZrO}_{2}$ contents. Accordingly, the distribution of $\mathrm{ZrO}_{2}$ particles in both $\mathrm{AZ4}$ nanocomposites specimens is homogenous, while that of AZ16 samples decreases. Importantly, an opposite trend is observed for porosity where it increases by increasing of $\mathrm{ZrO}_{2}$ particles in the studied specimens. However, the elevation of sintering temperature to $570{ }^{\circ} \mathrm{C}$ causes promotion for diffusion process during the heating process which results in better densification behavior, i.e. nearly reaches full density. The contact border between particles is seemed to be growing and indicates the achievement of strong nano- $\mathrm{ZrO}_{2}$-matrix interfacial bonding, during sintering of the nanocomposites samples, and the absence of pores, even in the area of $\mathrm{ZrO}_{2}$ particles. 

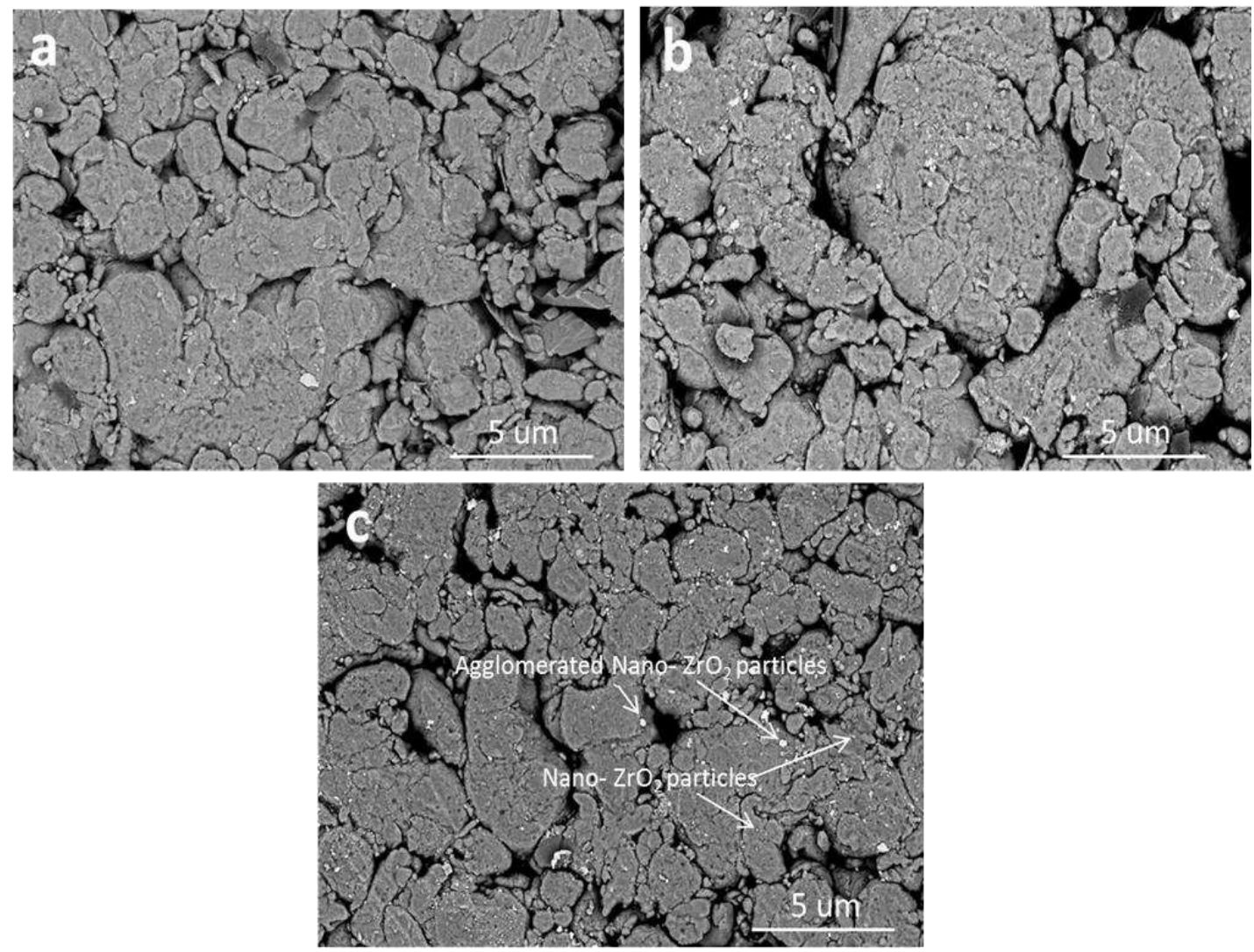

Fig.5. SEM images of a) AZ0, b) AZ4 and c) AZ16 compacted samples. 

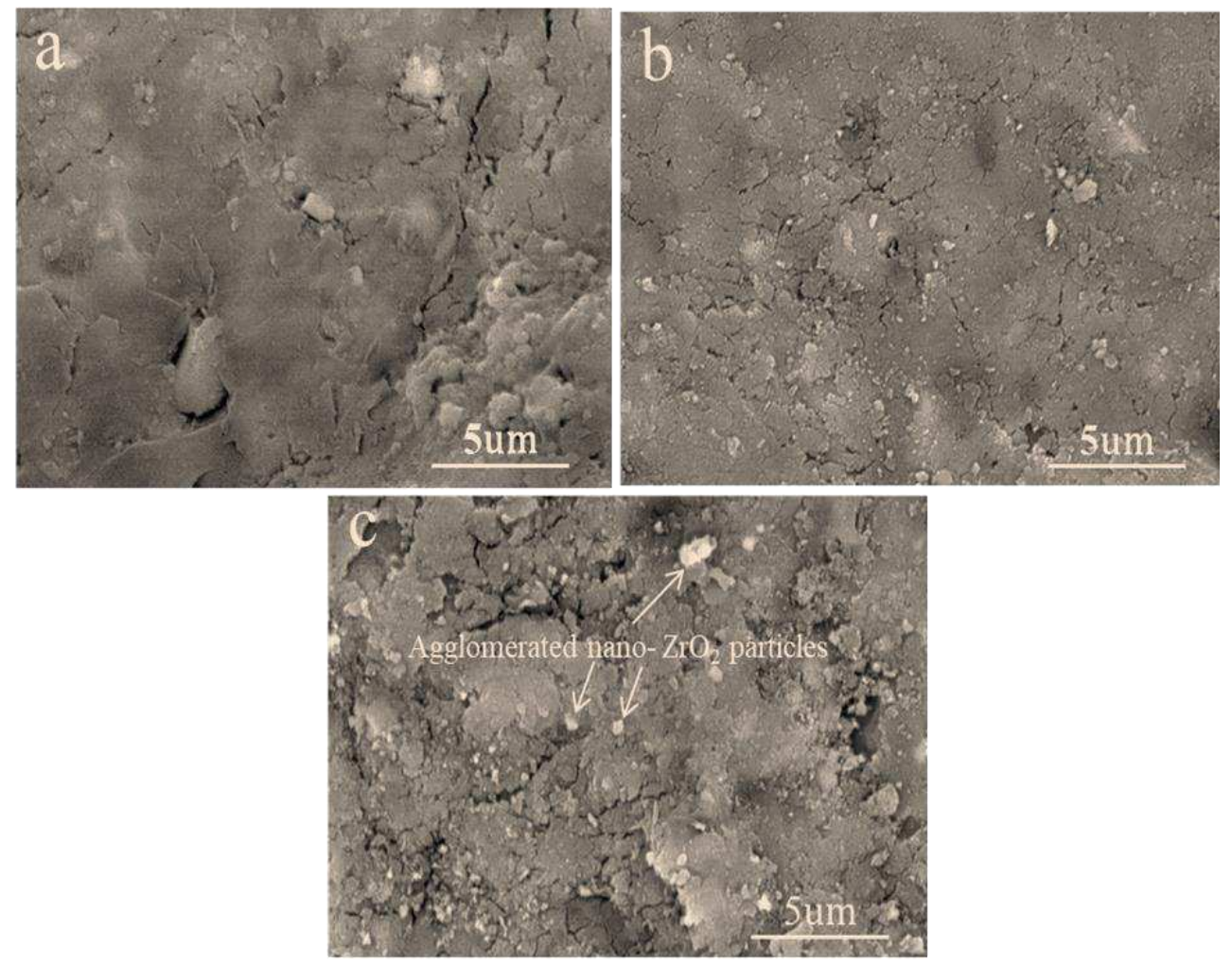

Fig.6. SEM micrographs of a) AZ0, b) AZ4 and c) AZ16 samples sintered at $470{ }^{\circ} \mathrm{C}$. 

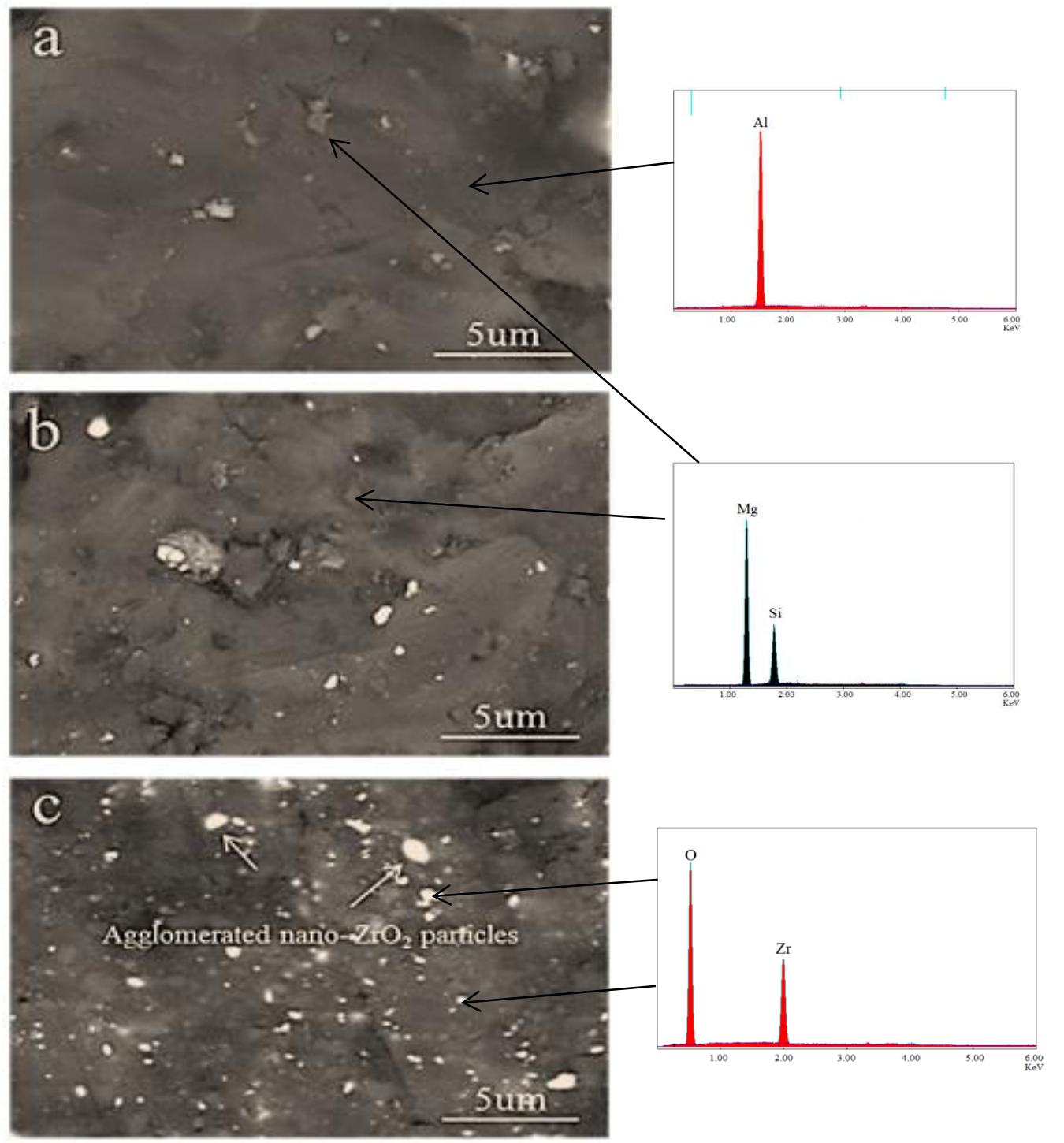

Fig.7. SEM micrographs of a) AZ0, b) AZ4 and c) AZ16 samples sintered at $570{ }^{\circ} \mathrm{C}$ along with their corresponding EDS patterns. 


\subsection{Thermal expansion behavior}

It cannot be denied that thermal expansion behavior is a useful property where it is closely correlated to thermo-mechanical applications and therefore, it can be extensively used for engine components as well as space structures. With regard to the importance of thermo-mechanical purposes in industrial field, metals suffer from their low thermal stability which requires a solution for this problem. It is important to note that the matching of CTE between metal matrix and ceramic reinforcement is a critical point which needs careful adjustment. Fig. 8 depicts the relative thermal expansion $(\Delta \mathrm{l} / \mathrm{l})$ behavior of the sintered $\mathrm{Al}$ alloys and nanocomposites samples in the temperature range $30-400{ }^{\circ} \mathrm{C}$. In the specified temperature range, the un-reinforced $\mathrm{Al}$ alloy matrix has higher $\Delta 1 / 1$ range from $0.679 \times 10^{-3}$ to $9.97 \times 10^{-3}$ compared with $0.495 \times 10^{-3}$ to $6.45 \times 10^{-3}$ for the composite contains 16 wt.\% of $\mathrm{ZrO}_{2}$ particles (AZ16). Fig. 9 illustrates the changes in CTE of the sintered samples calculated from the slope of thermal expansion curve (Fig. 8). It can be observed that increased $\mathrm{ZrO}_{2}$ contents cause reduction in $\mathrm{CTE}$ values. However, the elevation of sintering temperature leads to increase in CTE values. As expected, the addition of $\mathrm{ZrO}_{2}$ particles, into $\mathrm{Al}$ alloy matrix, significantly reduces the CTE of nanocomposites samples. This result is confirmed by the fact that $\mathrm{CTE}$ of $\mathrm{ZrO}_{2}$ is lower than that of $\mathrm{Al}$ alloy matrix and by this way, the thermal expansion of $\mathrm{Al}$ is effectively constrained providing good enhancement for dimensional stability of $\mathrm{Al}$ alloy matrix [36]. On the other hand, the addition of ceramic reinforcements $\left(\mathrm{ZrO}_{2}\right.$ particles) to metal matrix ( $\mathrm{Al}$ alloy) causes residual stresses in the matrix due to mismatch of the CTE values between Al alloy matrix and $\mathrm{ZrO}_{2}$ particles. The thermal stresses arising in $\mathrm{Al}$ alloy matrix leads to plastic deformation in the matrix and subsequently, it has an important role in improving the strength of nanocomposites [37]. 


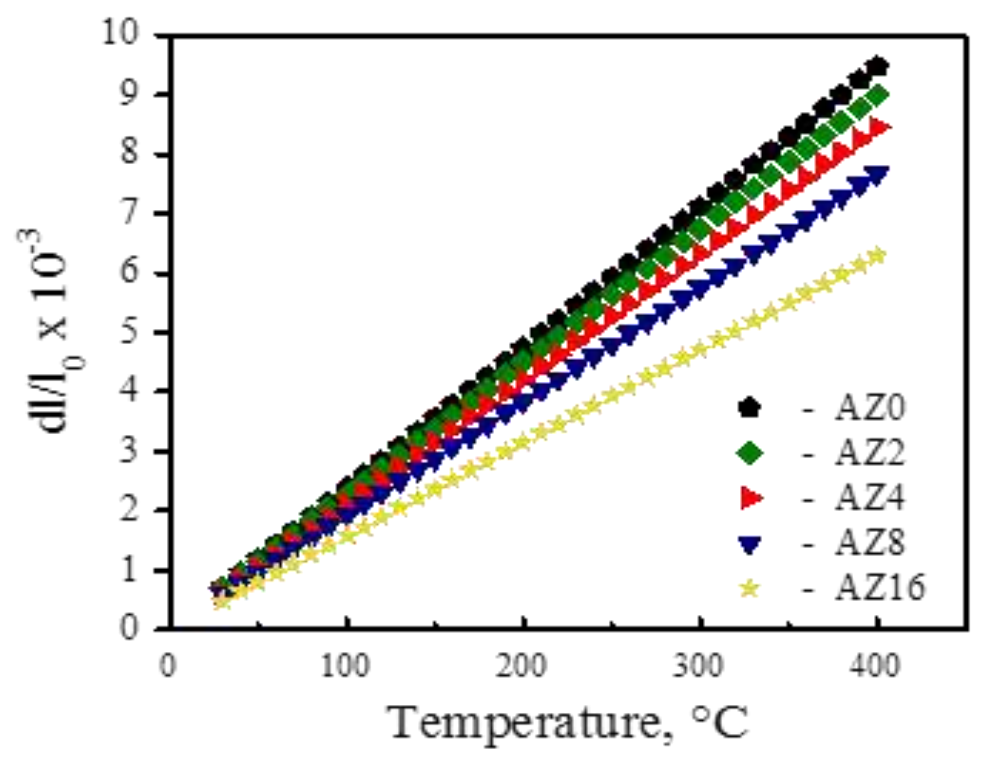

Fig. 8. Thermal expansion behavior of samples versus $\mathrm{ZrO}_{2}$ contents.

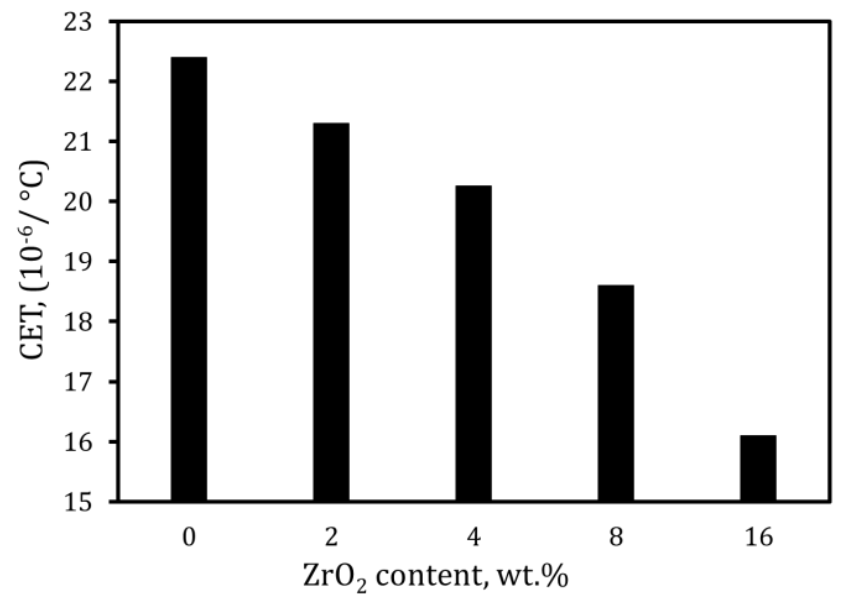

Fig.9. The changes in CTE values versus $\mathrm{ZrO}_{2}$ contents of the sintered nanocomposites.

\subsection{Elastic and mechanical properties}

The longitudinal $\left(\mathrm{V}_{\mathrm{L}}\right)$ and shear ultrasonic velocities $\left(\mathrm{V}_{\mathrm{S}}\right)$ results were measured using a non-destructive test (NDT) ultrasonic technique for samples sintered at 570 
${ }^{\circ} \mathrm{C}$ as shown in Fig. 10. It is interesting to see that ultrasonic velocities increase by increasing $\mathrm{ZrO}_{2}$ contents. The results in figure indicate that with increase in $\mathrm{ZrO}_{2}$ contents from 0 to $16 \mathrm{wt} . \%$, the $\mathrm{V}_{\mathrm{L}}$ and $\mathrm{V}_{\mathrm{S}}$ values of the samples range from 5886.4 to 7510.2 and 3205.6 to $4027.2 \mathrm{~ms}^{-1}$, respectively. As indicated by this figure, the elastic moduli exhibit the same trend for ultrasonic velocities. The elastic moduli of the investigated nanocomposites samples are shown in Fig. 11. It is clear from the figure that the family of elastic moduli exhibits the same trend for ultrasonic velocities. For example, the $\mathrm{AZ0}$ sample (i.e. the free content of $\mathrm{ZrO}_{2}$ particles), the results for the elastic modulus and Poisson's ratio are $89.6 \mathrm{GPa}$ and 0.2895 , respectively. Interestingly, they increase to $150.5 \mathrm{GPa}$ and 0.2982 , respectively when $\mathrm{ZrO}_{2}$ refinement increases to $16 \mathrm{wt}$ \% (AZ16). This marked improvement of ultrasonic velocities and elastic moduli due to the addition of highly hard nano- $\mathrm{ZrO}_{2}$ particles as reinforcement and this fully corresponds to the precise results of microhardness and compressive strength. 


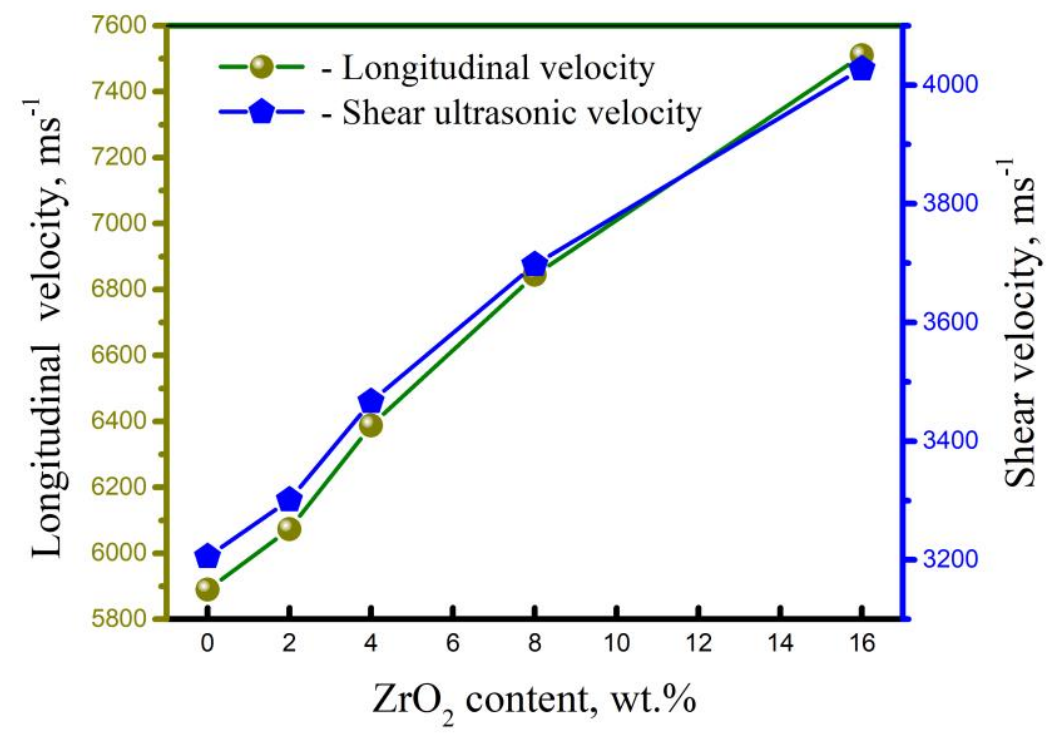

Fig.10. Ultrasonic velocities of nanocomposites samples sintered at 570 ${ }^{\circ} \mathrm{C}$ versus different $\mathrm{ZrO}_{2}$ contents.
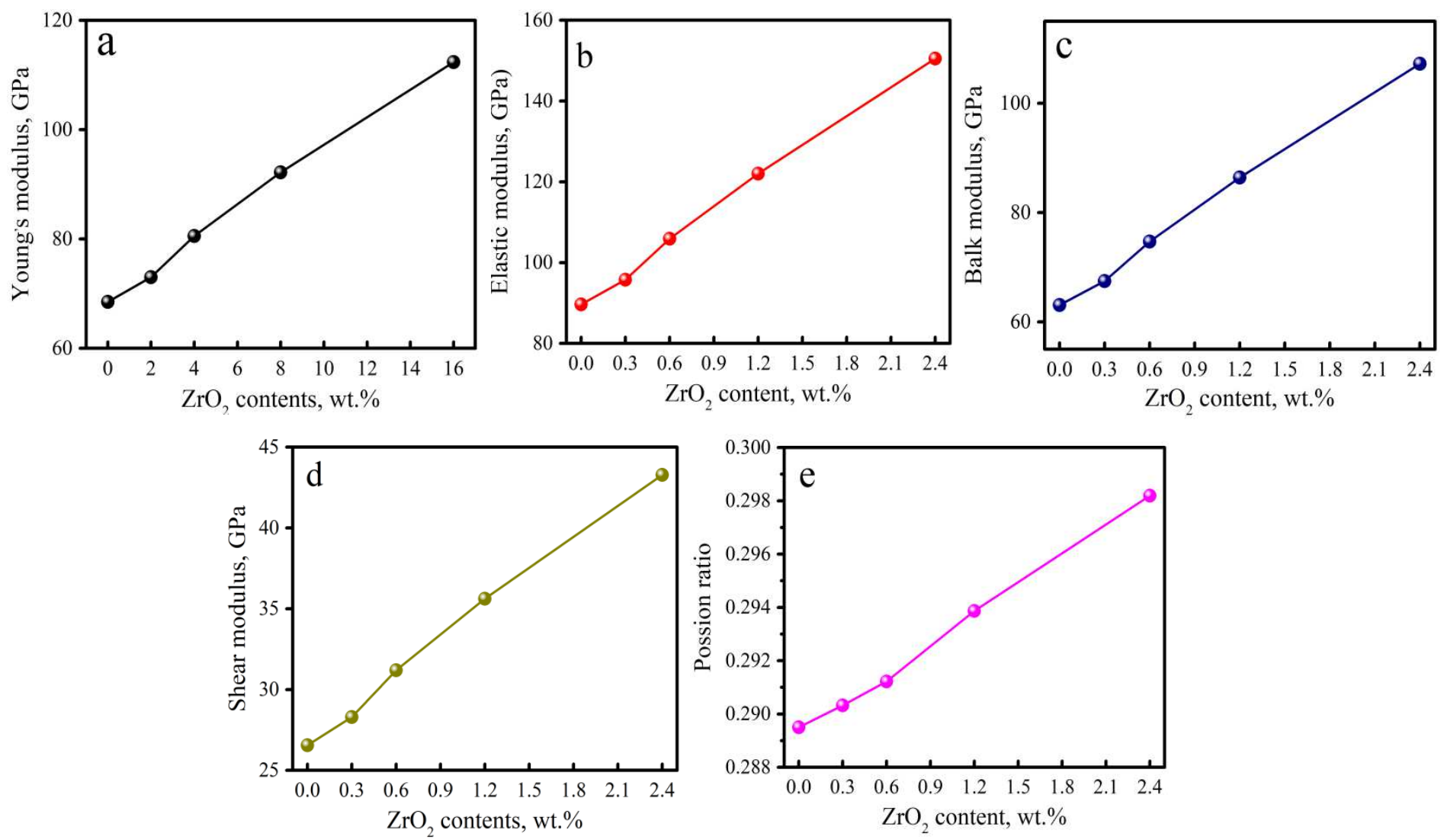

Fig.11. The group of elastic moduli of nanocomposites samples sintered at $570{ }^{\circ} \mathrm{C}$ versus different $\mathrm{ZrO}_{2}$ contents. 
The average microhardness values, $\mathrm{Hv}$, of the $\mathrm{Al}$ alloy and $\mathrm{Al}$ alloy- $\mathrm{ZrO}_{2}$ nanocomposite samples sintered at $570{ }^{\circ} \mathrm{C}$ are presented in Fig. 12. It is noted from the results that pronounced increases in microhardness values with increasing of different $\mathrm{ZrO}_{2}$ particles content in $\mathrm{Al}$ alloy matrix. The microhardness of $\mathrm{Al}$ alloy matrix increases from 431.12 to $1124.5 \mathrm{MPa}$ due to the addition of $16 \mathrm{wt}$. \% of $\mathrm{ZrO}_{2}$. Generally, the increase in microhardness of nanocomposites samples can be attributed to various reasons including homogenous distribution of reinforcement in matrix, decreased grains sizes of $\mathrm{Al}$ alloy matrix with successive increases in $\mathrm{ZrO}_{2}$ contents and the existence of hard ceramic particles (i.e. $\mathrm{ZrO}_{2}$ ) [9]. This enhancement can be better understood by noting the following eqn. (6) [11].

$\mathrm{H}_{\mathrm{c}}=\mathrm{H}_{\mathrm{Al}} \mathrm{F}_{\mathrm{Al}}+\mathrm{H}_{\mathrm{Z}} \mathrm{F}_{\mathrm{Z}}$

where, $\mathrm{H}_{\mathrm{c}}, \mathrm{H}_{\mathrm{Al}}$ and $\mathrm{H}_{Z}$ are microhardness of the nanocomposite, matrix, and reinforcement. On the other hand, $\mathrm{F}_{\mathrm{Al}}$ and $\mathrm{F}_{\mathrm{Z}}$ are the volume fraction of matrix and reinforcement, respectively.

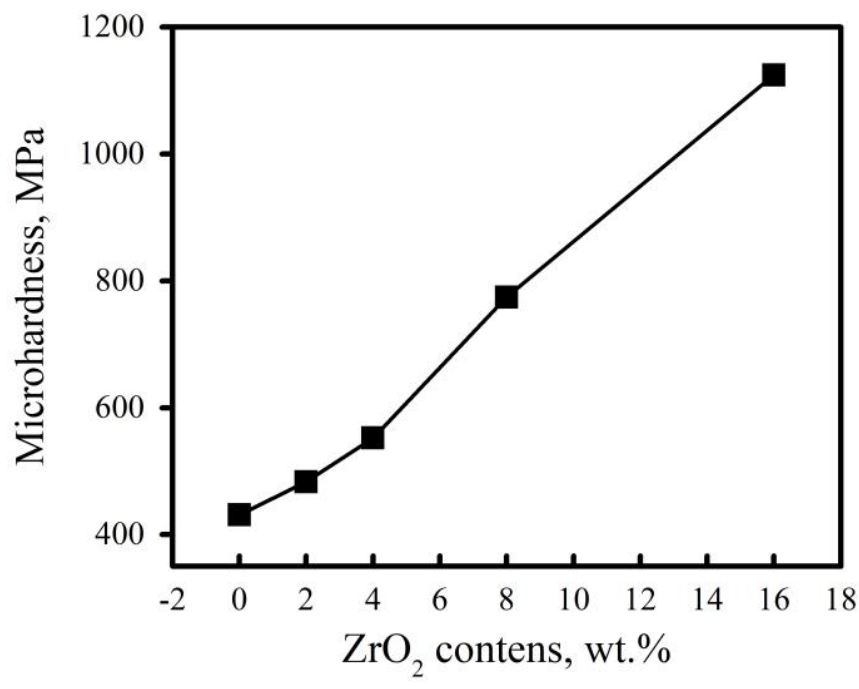

Fig.12. Microhardness of nanocomposites samples sintered at $570{ }^{\circ} \mathrm{C}$ versus $\mathrm{ZrO}_{2}$ contents. 
Fig. 13 shows the compressive stress-strain curves of samples. It can be observed that, for the same sintering temperature, Al alloy (AZ0) has a lower yield end compressive strengths and higher elongation than the other samples (AZ2, AZ4, AZ8 and AZ16). From the graphs obtained from the compression tests of the AZ0, AZ2, AZ4, AZ8 and AZ16 nanocomposites samples, the values of ultimate compression strength $\left(\sigma_{\mathrm{ucs}}\right)$, yield strength $\left(\sigma_{\mathrm{y}}\right)$, and elongation $(\varepsilon)$ were calculated and listed in Table 2. According to the results, both $\sigma_{\mathrm{ucs}}$ and $\sigma_{\mathrm{y}}$ of all nanocomposites samples gradually increase, while elongation reduces with increasing of $\mathrm{ZrO}_{2}$ contents which are in a good agreement with the observed trend in their microhardness results as shown in Fig. 8. The $\sigma_{\text {ucs }}, \sigma_{y}, \varepsilon$ are $263.82 \mathrm{MPa}$, 37.57 MPa, $19.8 \%$ for AZ0, respectively and for AZ16 were $383.46 \mathrm{MPa}, 92.25$ $\mathrm{MPa}, 12.9 \%$, respectively. Generally, many factors are responsible for the increases in ultimate and yield strength, while the decreases in the elongation of $\mathrm{Al}$ alloy matrix reinforced with different $\mathrm{ZrO}_{2}$ content is influenced by the following factors:

(i) Thermal-mismatch strengthening

Thermal mismatch strengthening is related to the large difference between CTE of $\mathrm{Al}$ alloy matrix and $\mathrm{ZrO}_{2}$ particles which contributes to producing thermally induced residual stresses [38]. Even small temperature changes, the thermal stresses generated in $\mathrm{Al}$ alloy matrix and greatly contribute to high dislocation density in vicinity of the interface and therefore, strengthen the nanocomposite.

(ii) Orowan strengthening The Orowan strengthening effect plays a key role in the enhancement of mechanical properties of $\mathrm{Al}$ matrix nanocomposites which resulting from homogenous dispersion of hard $\mathrm{ZrO}_{2}$ phase into $\mathrm{Al}$ alloy matrix which acts as a barrier for dislocation movement. Consequently, dislocation loops are created 
around $\mathrm{ZrO}_{2}$ particles causing an increase in the stress required for more deformation.

(iii) Load transfer from the $\mathrm{Al}$ alloy to the $\mathrm{ZrO}_{2}$ nanoparticles

During compressive testing, the load transfer, $\sigma_{\text {load }}$, between the hard $\mathrm{ZrO}_{2}$ particles and $\mathrm{Al}$ alloy, especially, if the connection between $\mathrm{ZrO}_{2}$ particles reinforcement and Al alloy matrix is good enough as explained by eqn. (1) [39]:

$\sigma_{\text {load }}=0.5 \mathrm{~V}_{\mathrm{f}} \sigma_{\mathrm{Ym}}$

where $\sigma_{\mathrm{Ym}}$ is the yield strength of matrix

It can be concluded that work hardening capacity $\left(\mathrm{H}_{\mathrm{c}}\right)$ of samples is reduced by adding various $\mathrm{ZrO}_{2}$ contents. The $\mathrm{H}_{\mathrm{c}}$ of nanocomposites samples can be calculated using the value of $\sigma_{\mathrm{ucs}}$ and $\sigma_{\mathrm{y}}$ according to eqn. (2):

$\mathrm{Hc}=\frac{\sigma_{\mathrm{UCS}}-\sigma_{\mathrm{Y}}}{\sigma_{\mathrm{Y}}}$

The value of $\mathrm{H}_{\mathrm{c}}$ of nanocomposites was calculated by eqn. (2) and represented in Table 3. It is interesting to observe that $\mathrm{H}_{\mathrm{c}}$ of pressed nanocomposites decreases with the increase in the $\mathrm{ZrO}_{2}$ nanoparticle content. The $\mathrm{H}_{\mathrm{c}}$ of the nanocomposites is dependent on its yield strength, which is further correlated to grains sizes based on the Hall-Petch eqn. If the grains sizes decrease, the difference in the flow resistance between the grain boundaries is also reduced leading to an increase in the yield strength which consequently, leads to decreased work hardening [40]. 


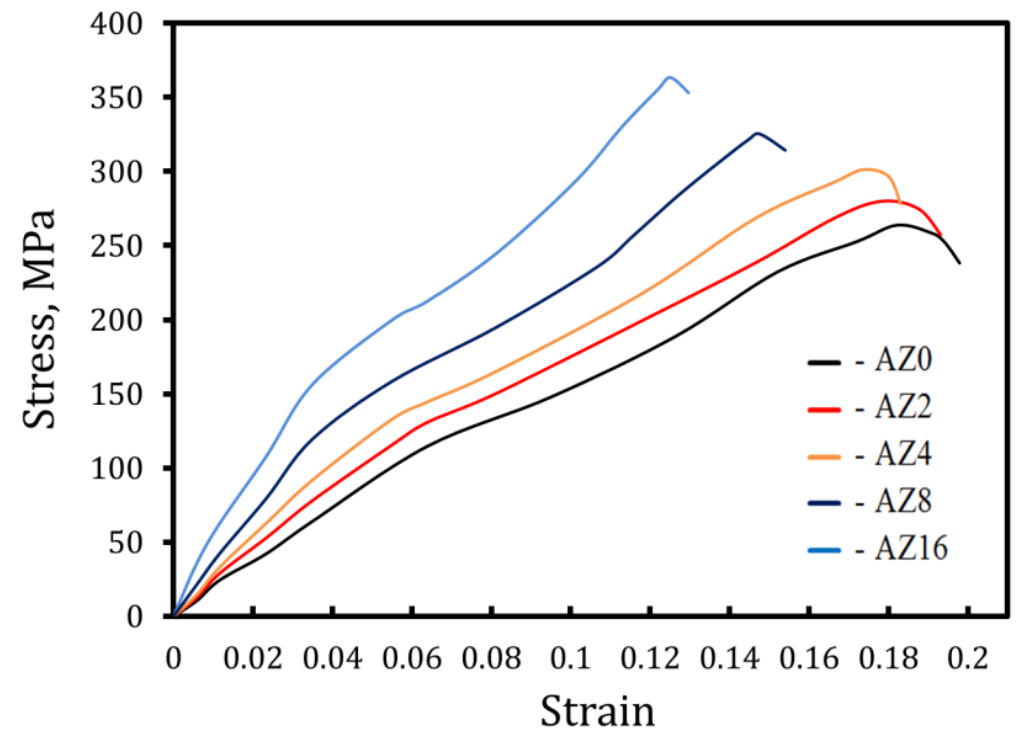

Fig.13. Compressive stress versus strain curve of $\mathrm{Al}$ alloy- $\mathrm{ZrO} \mathrm{O}_{2}$ samples sintered at $570{ }^{\circ} \mathrm{C}$.

Table 2. Ultimate compressive strength, yield strength, elongation and work hardening capacity of samples.

\begin{tabular}{ccccc}
\hline Sample & $\boldsymbol{\sigma}_{\text {ucs }(\mathbf{M P a})}$ & $\boldsymbol{\sigma}_{\mathbf{y}(\mathbf{M P a})}$ & $\boldsymbol{\varepsilon}(\boldsymbol{\%})$ & $\mathbf{H}_{\mathbf{c}}$ \\
\hline $\mathbf{A Z 0}$ & 263.82 & 37.57 & 19.8 & 6.02 \\
$\mathbf{A Z 2}$ & 279.92 & 40.91 & 19.3 & 5.84 \\
$\mathbf{A Z 4}$ & 301.26 & 47.81 & 18.3 & 5.30 \\
$\mathbf{A Z 8}$ & 325.35 & 67.84 & 15.4 & 3.80 \\
$\mathbf{A Z 1 6}$ & 363.46 & 92.25 & 12.9 & 2.94 \\
\hline
\end{tabular}




\subsection{Wear analysis}

Fig. 14 represents the variations in weight loss and wear rate of AZ0, AZ2, AZ4, AZ8 and AZ16 samples with different applied loads of test (10, 20 and 40 $\mathrm{N})$. The results point out that the wear resistance of nanocomposites samples tends to increase with an increase in $\mathrm{ZrO}_{2}$ contents, while it is decreased with increasing of the load. The weight loss of un-reinforced sample (i.e. AZ0) at applied loads, i.e. 10,20 and $40 \mathrm{~N}$ is $0.016,0.0137$ and $0.0125 \mathrm{~g}$, respectively. For the sample containing 16 wt. $\%$ of $\mathrm{ZrO}_{2}$ (i.e. AZ16) at the same applied loads, the weight loss is $0.01,0.0083$ and $0.0078 \mathrm{~g}$, respectively. Furthermore, the wear rate of AZ0, AZ2, AZ4, AZ8 and AZ16 nanocomposites samples when the applied load equals to $40 \mathrm{~N}$ is $0.027,0.025,0.023,0.02$ and $0.017 \mathrm{mg} / \mathrm{s}$, respectively. Undoubtedly, the addition of ceramics particles (i.e. $\mathrm{ZrO}_{2}$ ) has a positive outcome in the synthesized composites in which wear resistance is found to be effectively improved [41]. To explain the enhancement of wear resistance of nanocomposites, it is important to highlight that the addition of $\mathrm{ZrO}_{2}$ particles to $\mathrm{Al}$ alloy results in an enhancement in the microhardness and strength of nanocomposites samples as previously discussed and therefore, the wear rate decreases according to Archad eqn. (3) [14]:

$$
\mathrm{W}=\frac{\mathrm{kP}}{\mathrm{H}}
$$

where $\mathrm{W}$ is wear rate, $\mathrm{K}$ is a wear coefficient (constant value), $\mathrm{P}$ is the load and $\mathrm{H}$ is the Vickers hardness of the specimen.

Furthermore, the increasing of microhardness is consistent with a decrease in a real area of contact. It is well-accepted that real area of contact can be expressed in terms of the ratio of the normal load to the hardness of the pin material and accordingly, decreased real area of contact leads to considerable decreases in wear rate [42]. On the other hand, increases in weight loss and wear rate with increases in the applied load and the surface temperature encourage surface softening 
causing more surface and subsurface damage which in turn, results in decreased wear resistance [17]. One can say that both wear and loss of metals are highly dependent on an increase in the load as the initial fraction period works to fracture the surface layers leading to not only cleaning the surfaces but also increasing the strength of connections between surfaces. This process increases tillage effect between surfaces which in turn, increases the temperature between them resulting in adhesion as well as deformation at the surface layers driving more loss for metals [43].
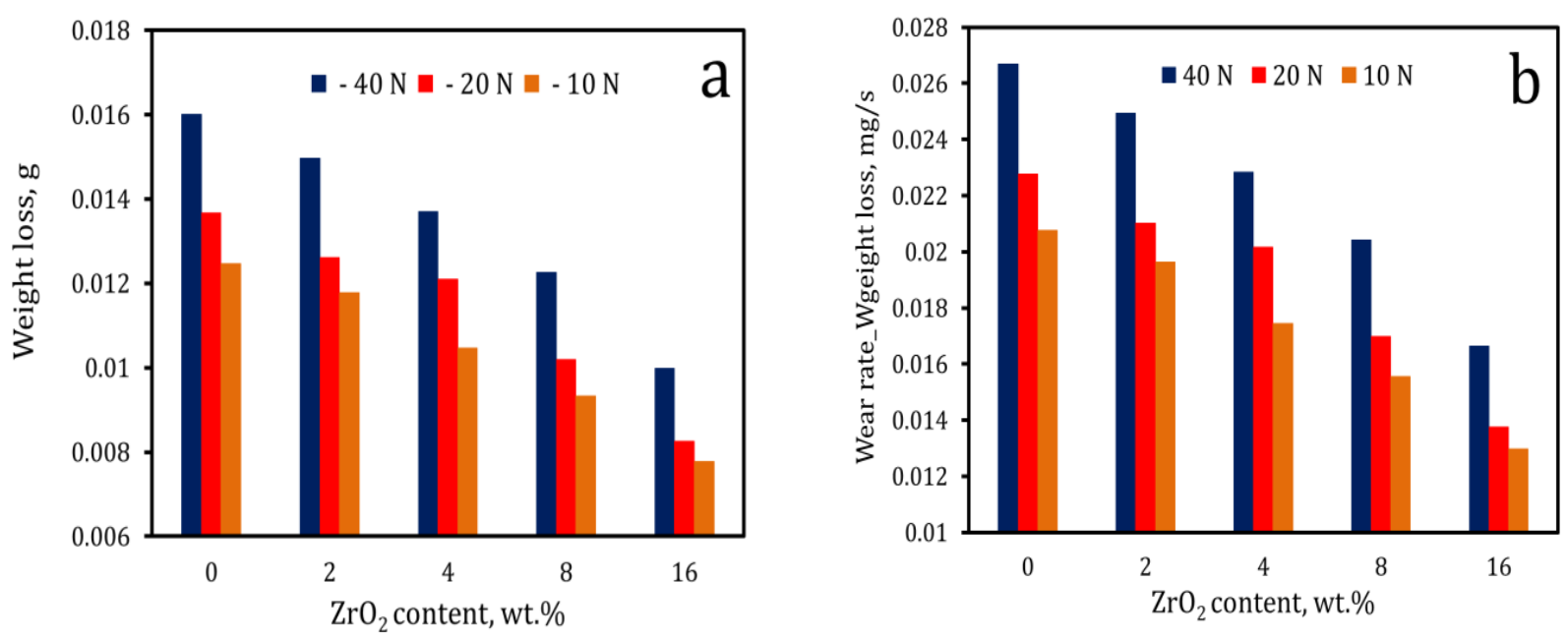

Fig.14. a) Weight loss and b) wear rate of specimens sintered at $570{ }^{\circ} \mathrm{C}$ for different applied loads.

\subsection{Corrosion analysis}

The weight loss method was used to evaluate the corrosion behavior of $\mathrm{Al}$ or nanocomposites specimens in acidic medium. Generally, there are many factors affecting the corrosion behavior of the studied nanocomposites such as compaction, density, sintering and weight percentages of $\mathrm{ZrO}_{2}$ reinforcement. In this sense, weight loss and corrosion rate of AZ0, AZ2, AZ4, AZ8 and AZ16 sintered samples, immersed in $0.1 \mathrm{~N} \mathrm{HCl}$ at room temperature $\left(30{ }^{\circ} \mathrm{C}\right)$, as a 
function of exposure time were examined and represented in Fig. 13. It is interesting to observe that the weight loss of $\mathrm{Al}$ alloy matrix nanocomposites increases with increasing of exposure time and therefore, the corrosion rate decreases. The weight loss of sample increases with increases in the exposure time due to that increasing contact period with acidic medium results in decreases in corrosion rate [44]. The weight loss of AZ0 sample immersed for 24, 96 and $168 \mathrm{~h}$ are $18.04,32.52$ and $41.65 \mathrm{mg}$, respectively and for sample containing $16 \mathrm{wt} . \%$ of $\mathrm{ZrO}_{2}$ (i.e. AZ16), at the same immersion times, is $6.43,9.06$ and $11.52 \mathrm{mg}$, respectively. It could be also observed that both weight loss and corrosion rate decrease by increasing of $\mathrm{ZrO}_{2}$ contents. Generally, the ceramic reinforcements particles remain as it is, i.e. without noticeable corrosive behavior and therefore, the existence of $\mathrm{ZrO}_{2}$-particles in the surface of nanocomposites samples that will protect the surface layer in acidic medium [44.45]. The AZ0 sample shows that higher corrosion rate compared to that of AZ16 nanocomposites samples. The reason behind this result is that $\mathrm{ZrO}_{2}$ is a ceramic material which possesses high corrosion resistance, i.e. remains inert and not affected by the acid medium throughout the corrosion tests. The corrosion rate of AZ0, AZ2, AZ4, AZ8 and AZ16 samples immersed for $168 \mathrm{~h}$ are 1.63, 1.46, 1.36, 0.86 and $0.44 \mathrm{mmpy}$, respectively. 

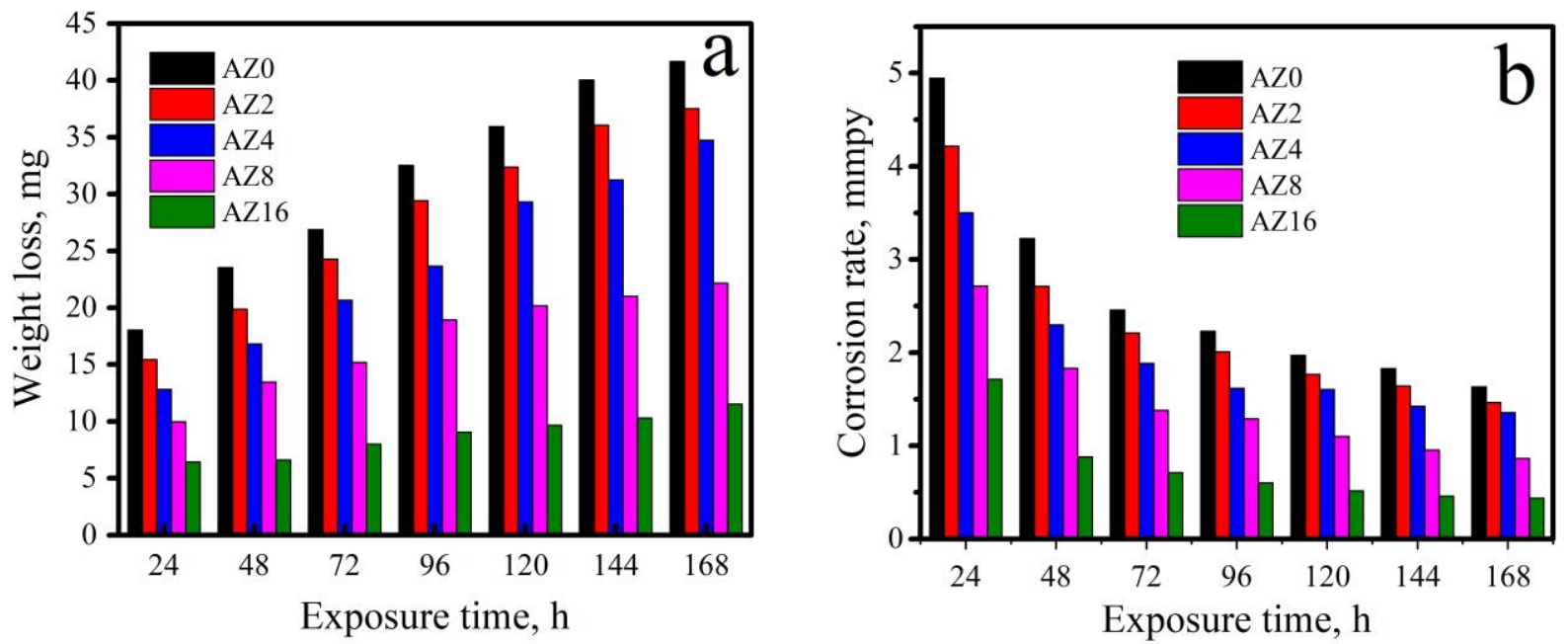

Fig.15. a) Weight loss and b) corrosion rate of specimens sintered at $570{ }^{\circ} \mathrm{C}$ for different applied loads.

\section{Conclusions}

In the current study $\mathrm{Al}-\mathrm{Cu}-\mathrm{Mg}$ alloy- $\mathrm{ZrO}_{2}$ nanocomposites was prepared using powder metallurgy, the following conclusions were drawn

- It was observed that the nanocomposites prepared by the mechanical alloying method had a good distribution of nano- $\mathrm{ZrO}_{2}$ particles in a matrix with noticeable agglomerations.

- The mechanical alloy technique can be used to produce an A12024 alloy matrix nanocomposite in which graphene sheet was uniformly distributed with few agglomerations.

- The particle size decreased with increasing the weight percentages of $\mathrm{ZrO}_{2}$ particles, until they reached $47.8 \mathrm{~nm}$ for the high contents of $\mathrm{ZrO}_{2}$ (i.e. AZ16 sample).

- The relative density of the nanocomposite decreased with increasing $\mathrm{ZrO}_{2}$ contents while the apparent porosity had an opposite trend. 
- The measurement of thermal expansion reflected that the CTE of the Al alloy was decreased by about $28.2 \%$ with the addition of $16 \mathrm{wt} . \% \mathrm{ZrO}_{2}$ particles, indicating high dimensional stability of nanocomposites samples.

- The ultrasonic velocities of the sintered samples increased with the increase in $\mathrm{ZrO}_{2}$ contents and thus, increase the value of elastic moduli. The elastic and bulk moduli were enhanced to 68 and $70 \%$, respectively after adding 16 wt. $\%$ of $\mathrm{ZrO}_{2}$

- Microhardness, ultimate and yield strength were improved, while the elongation and work hardening were reduced as the weight percentages of $\mathrm{ZrO}_{2}$ have been increased. The maximum values of the microhardness and ultimate strength were recorded for the AZ16 sample, i.e. $~ 1.8$ and 2.1 times, respectively higher than those of the AZ0 sample.

- The wear rates of specimens decreased with increasing $\mathrm{ZrO}_{2}$ contents while increasing with increasing the application. For an applied load of $40 \mathrm{~N}$, the wear rate of the $\mathrm{Al}$ alloy decreased by approximately $37.6 \%$ by adding 16 wt. $\% \mathrm{ZrO}_{2}$ particles.

- The corrosion rate of nanocomposites has been found to be reduced by increasing the exposure time and weight percentages of $\mathrm{ZrO}_{2}$ particles.

\section{Acknowledgment}

This project was funded by the deanship of scientific research (DSR) at King Abdulaziz University, Jeddah under grant No. (RG-1-150-38). The authors therefore gratefully acknowledges technical and financial support from DSR.

\section{References}

[1] M.A. Taha , R.A. Youness, M.A. Ibrahim, Evolution of the Physical, Mechanical and Electrical Properties of SiC-Reinforced Al 6061 Composites Prepared by Stir Cast Method, Biointerface. Res. Appl. 11(2), 8946 - 8956 (2021). 
[2] B. Park, D. Lee, I. Jo, S.B. Lee, S.K. Lee, S. Cho, Automated quantification of reinforcement dispersion in $\mathrm{B} 4 \mathrm{C} / \mathrm{Al}$ metal matrix composites, Compos. 181, 107584 (2020).

[3] M.F Zawrah, H. Mostafa, M.A Taha, Effect of SiC content on microstructure, mechanical and electrical properties of sintered Al-20Si-xSiC nanocomposites fabricated by mechanical alloying, Mater. Res. Express 61, 25014 (2019).

[4] Y. Han, D. Gallant, X.G. Chen, Investigation on corrosion behavior of the AlB4C metal matrix composite in a mildly oxidizing aqueous environment. Corrosion. 67, (2011) 1-11.

[5] Y.M. Han, X.G. Chen, Electrochemical behavior of $\mathrm{Al}-\mathrm{B}_{4} \mathrm{C}$ metal matrix composites in $\mathrm{NaCl}$ solution. Mater. 8, 6455-6470 (2015).

[6] W.S. AbuShanab, E.B. Moustafa, E. Ghandourah, M. A. Taha, Effect of graphene nanoparticles on the physical and mechanical properties of the Al2024-Graphene nanocomposites fabricated by powder metallurgy, Results. Phys. 19, 103343 (2020).

[7] Q. Bai, L. Zhang, L. Ke, P. Zhu, Y. Ma, S. Xi, B. Zhou, The effects of surface chemical treatment on the corrosion behavior of an $\mathrm{Al}-\mathrm{B}_{4} \mathrm{C}$ metal matrix composite in boric acid solutions at different temperatures, Mat. Today. In press (2020)

[8] E.M. Sherif, H.S. Abdo, K.A. Khalil, A.M. Nabawy, Effect of Titanium Carbide Content on the Corrosion Behavior of Al-TiC Composites Processed by High Energy Ball Mill, Int. J. Electrochem. Sci. 11, 4632 - 4644 (2016).

[9] T.S. Mahmoud, E.S.Y. El-Kady, A.S.M. Al-Shihiri, Corrosion behaviour of $\mathrm{Al} / \mathrm{SiC}$ and $\mathrm{Al} / \mathrm{Al}_{2} \mathrm{O}_{3}$ nanocomposites, Mater. Res. 15(6), 903-910 (2012).

[10] A Zulfia, T Zhakiah, D Dhaneswara, Sutopo, Characteristics of Al-Si-Mg reinforced sic composites produced by stir casting route, Mater. Sci. Eng, 202 (2017) 012089. 
[11] A. Canakci, T. Varol, F. Erdemir, The Effect of Flake Powder Metallurgy on the Microstructure and Densification Behavior of B4C Nanoparticle-Reinforced Al-Cu-Mg Alloy Matrix Nanocomposites, Arab. J. Sci. Eng. 41, 17811796 (2016).

[12] E.B. Moustafa, M.A. Taha, Evaluation of microstructure, thermal and mechanical properties of $\mathrm{Cu} / \mathrm{SiC}$ nanocomposites fabricated by mechanical alloying, Int. J. Miner. Metall. (2020).

[13] E.B. Moustafa, W.S. AbuShanab, E. Ghandourah, M.A. Taha, Microstructural, mechanical and thermal properties evaluation of $\mathrm{AA} 6061 / \mathrm{Al}_{2} \mathrm{O}_{3}$ BN hybrid and mono nanocomposite surface, JMRT 9 (6) 15486-15495 (2020). [14] M.A. Taha, M.F. Zawrah, Effect of nano $\mathrm{ZrO}_{2}$ on strengthening and electrical properties of $\mathrm{Cu}$-matrix nanocomposits prepared by mechanical alloying, Ceram. Int. 43 , 12698-12704 (2017).

[15] R. Tyagi, Synthesis and tribological characterization of in situ cast Al-TiC composites, Wear. 259, 569-576 (2005).

[16] M.F. Zawrah, M.A. Taha, H. Abo Mostafa, In-situ formation of $\mathrm{Al}_{2} \mathrm{O}_{3} / \mathrm{Al}$ core-shell from waste material: Production of porous composite improved by grapheme, Ceram. Int. 44, 10693-10699 (2018).

[17] E.B. Moustafa, M.A. Taha, Preparation of high strength graphene reinforced Cu-based nanocomposites via mechanical alloying method: microstructural, mechanical and electrical properties, Appl. Phys. A-Mater.126, 220 (2020).

[18] O.R. Pérez, J. A. García-Hinojosa, F. J. Rodríguez Gómez, S. Mejia-Sintillo2, V.M. Salinas-Bravo, R. Lopes-Sesenez, J.G. Gonzalez-Rodriguez, C.A. GarciaPérez, Corrosion Behavior of A356/SiC Alloy Matrix Composites in 3.5\% $\mathrm{NaCl}$ Solution, nt. J. Electrochem. Sci.14, 7423-7436 (2019)

[19] E.B. Moustafa, A.O. Mosleh, Effect of (Ti-B) modifier elements and FSP on 5052 aluminum alloy, Alloy. Compd. 825, 153745 (2020). 
[20] M. Dhanashekar, V.S. Kumar, Squeeze Casting of Aluminium Metal Matrix Composites- An Overview, Procedia. Eng. 97, 412-420 (2014).

[21] S. Gopalakrishnan, N. Murugari, Production and wear characterization of AA 6061 matrix titanium diboride particulate reinforced composite by enhanced stir casting method, Compos. B. 43, 302-308 (2012).

[22] R.Dalai, S. Nath, D.K. Mishra, G. Behera, Fabrication of an Al matrix hybrid composite reinforced with $\mathrm{Cu}, \mathrm{Al}_{2} \mathrm{O}_{3}$ and $\mathrm{TiC}$ by mechanical alloying, Mater. Today, 26,1841-1844 (2020).

[23] R.A. Youness, M.A. Taha, M. Ibrahim, Dense alumina-based carbonated fluorapatite nanobiocomposites for dental applications, Mater. Chem. Phys. 257, $123264(2021)$.

[24] R.A. Youness, M.A. Taha, M.A. Ibrahim, In vitro bioactivity, molecular structure and mechanical properties of zirconia-carbonated hydroxyapatite nanobiocomposites sintered at different temperatures, Mater. Chem. Phys. 239, 122011239 (2020).

[25] M.A. Taha, A.H. Nassar, M.F. Zawrah, In-situ formation of composite having hard outer layer based on aluminum dross reinforced by $\mathrm{SiC}$ and $\mathrm{TiO}_{2}$, Constr. Build. Mater. 248, 118638 (2020).

[26] M.A. Taha, R.A. Youness, M. Ibrahim, Biocompatibility, physico-chemical and mechanical properties of hydroxyapatite-based silicon dioxide nanocomposites for biomedical applications, Ceram.Int. 46, 23599-23610 (2020).

[27] A.E.A. Al-maamari, A.A Iqbal, D.M Nuruzzaman, Mechanical and tribological characterization of self-lubricatingMg-SiC-Gr hybrid metal matrix composite (MMC) fabricated viamechanical alloying, J. Sci-Adv Mater Dev. 5, 535-544 (2020) 
[28] M.A. Taha, R.A. Youness, M.F. Zawrah, Review on nanocomposites fabricated by mechanical alloying Int. J. Miner. Metall. 26(9) 1047-1058 (2019) [29] W.S. AbuShanab, E.B. Moustafa, M.A. Taha, R.A. Youness, Synthesis and structural properties characterization of titania/ zirconia/calcium silicate nanocomposites for biomedical applications, Appl. Phys. A. 787, 1-12 (2020). [30] M.A. Taha, R.A. Youness, M.F. Zawrahc, Phase composition, sinterability and bioactivity of amorphous nano- $\mathrm{CaOSiO}_{2}-\mathrm{CuO}$ powder synthesized by sol-gel technique, Ceram. Int. 46, 24462-24471(2020).

[31] E.B. Moustafa, A. Melaibari, M. Basha, Wear and microhardness behaviors of AA7075/SiC-BN hybrid nanocomposite surfaces fabricated by friction stir processing, Ceramics International, 46 (2020) 16938-16943.

[32] M. Elmahdy, G. Abouelmagd, A.A. Mazen, Microstructure and properties of $\mathrm{Cu}-\mathrm{ZrO}_{2}$ nanocomposites synthesized by in situ Processing, Mater. Res. 21, 1-11 (2018).

[33] D. Ağaoğullar, Effects of $\mathrm{ZrC}$ content and mechanical alloying on the microstructural and mechanical properties of hypoeutectic Al-7 wt.\% $\mathrm{Si}$ composites prepared by spark plasma sintering, Ceram. Int. 45, 13257-13268 (2019).

[34] A. Wah, N. Muhamad, A.B. Sulon, R.N. Ahmad, Effect of Sintering Temperature on Density, Hardness and Strength of MIM Co30Cr6Mo Biomedical Alloy, J. Jpn. Soc. Powder. Metall. 63, 434- 437 (2016).

[35] R.A. Youness, M. A. Taha, M.A. Ibrahim, Effect of sintering temperatures on the in vitro bioactivity, molecular structure and mechanical properties of titanium/carbonated hydroxyapatite nanobiocomposites, Mol. Struct. 1150, 188195 (2017). 
[36] R. Murugesana, M. Gopal, G. Murali, Effect of $\mathrm{Cu}$, Ni addition on the CNTs dispersion, wear and thermal expansion behavior of Al-CNT composites by molecular mixing and mechanical alloying, App. Surf. Sci. 495, 143542 (2019).

[37] S. C. Okumus, S. Aslan, R. Karslioglu, D. Gultekin, H. Akbulut, Thermal expansion and thermal conductivity behaviors of al-Si/SiC/graphite hybrid metal matrix composites (MMCS), Mater. Sci. 18, 341-346 (2012).

[38] G. Chen, J. Wan, N. HE, H. Zhang, F. han, Y. Zhang, Strengthening mechanisms based on reinforcement distribution uniformity for particle reinforced aluminum matrix composites, Trans. Nonferrous Met. Soc. China. 28, 2395-2400. (2018).

[39] K. Habibnejad, R. Mahmudi, W. J. Poole, Enhanced properties of Mg-based nano-composites reinforced with $\mathrm{Al}_{2} \mathrm{O}_{3}$ nano-particles, Mater. Sci. Eng. A. 519, 198-203 (2009).

[40] A. Alizadeh, M. Maleki, A. Abdollahi, Preparation of super-high strength nanostructured $\mathrm{B}_{4} \mathrm{C}$ reinforced $\mathrm{Al}-2 \mathrm{Cu}$ aluminum alloy matrix composites by mechanical milling and hot press method: Microstructural, mechanical and tribological Characterization, Adv. Powder. Technol. 28, 3274-3287 (2017).

[41] H.G.P. Kumar, M.A. Xavior, assessment of mechanical and tribological properties of Al 2024- SiC - graphene hybrid composites, Procedia. Eng. 174, 992999 (2017).

[42] R. Tyagi, effect of TiC content on friction and wear behavior of Al-Tic composites, World Tribology congress, 1, 3-4 (2005).

[43] R.A. Al-Samarai, Haftirman, K.R. Ahmad, Y. Al-Douri, Effect of load and sliding speed on wear and friction of aluminum- silicon casting alloy, IJSRP. 2, 14 (2012).

[44] C.F. John, R.C. Paul, S.C.E. Singh, J. Jacobjose, T. Ramkumar, G.S. Hikku, R.K. Sharma, P. Sengottuvel, Corrosion behavior of $\mathrm{ZrC}$ particles reinforcement 
with Al-12Si composites by weight loss method using acidic media, Bull. Pol. Ac.: Tech. 66, 9-16 (2018).

[45] H.M. Zakaria, Microstructural and corrosion behavior of $\mathrm{Al} / \mathrm{SiC}$ metal matrix composites, Ain. Shams. Eng, 5, 831-838 (2014).

[46] M. S. Abubakar, B. Usman, Investigation of corrosion inhibition potential of ethanol extract of balanites aegyptiaca leaves on mild steel in $1 \mathrm{~m}$ hydrochloric acid solution, Mor. J. Chem. 7, 82-97 (2019). 


\section{Figures}
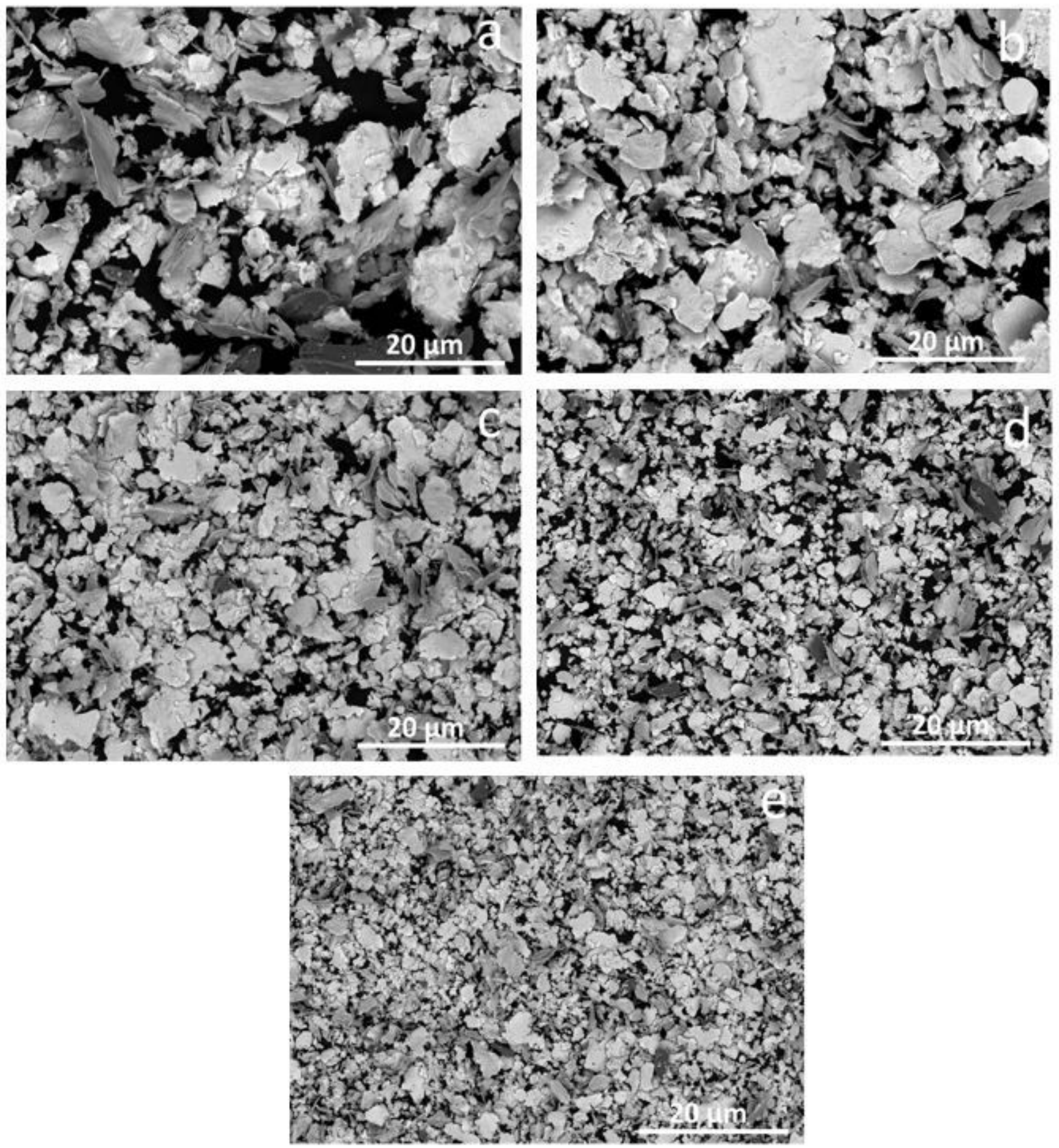

Figure 1

SEM micrographs of milled powders (a) AZ0, (b) AZ2, (c) AZ4, (d) AZ4 and(e) AZ16 samples. 


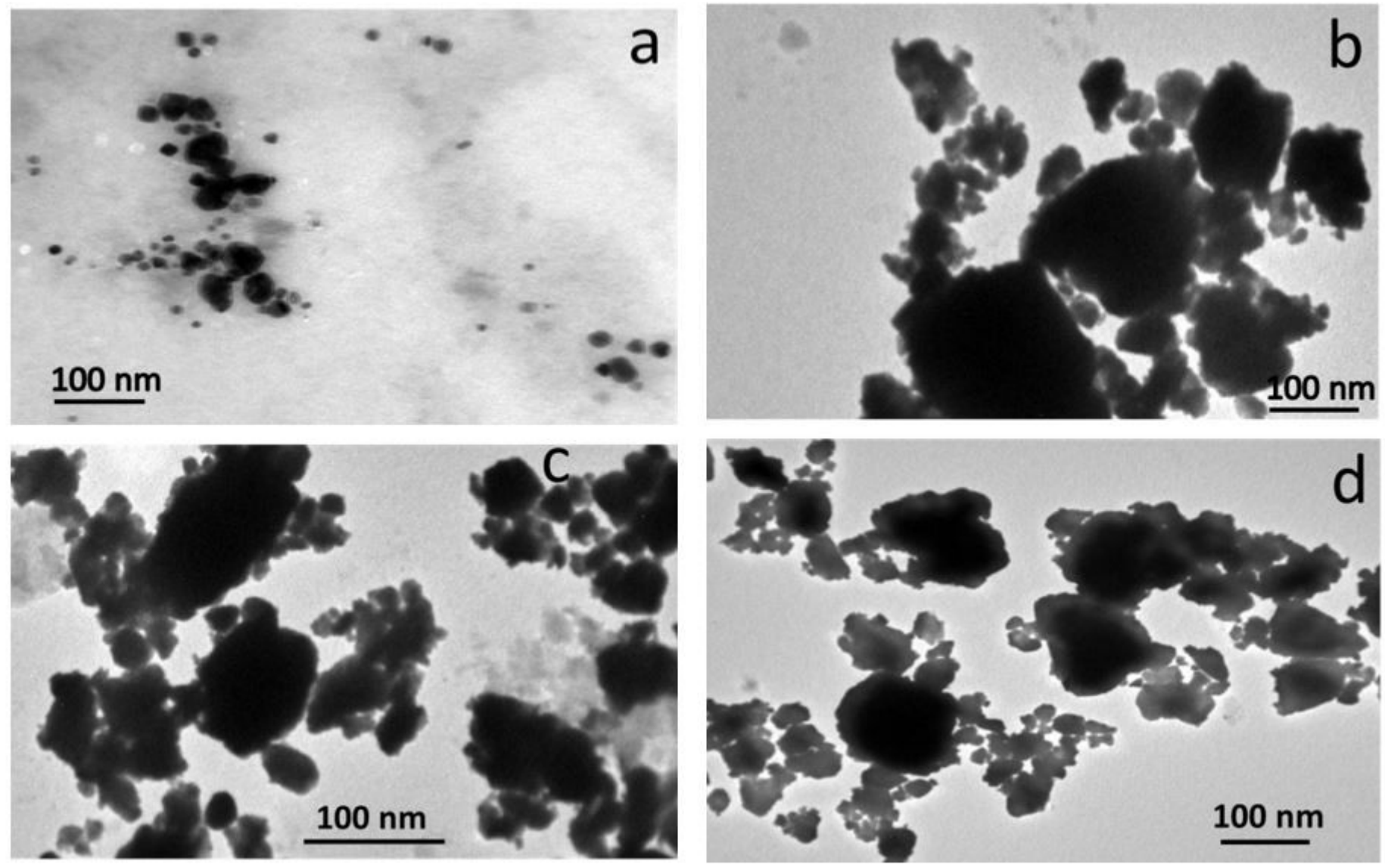

Figure 2

TEM micrographs of (a) as-received ZrO2 nanoparticles, (b) AZ0, (c) AZ8 and (d) AZ16 samples. 

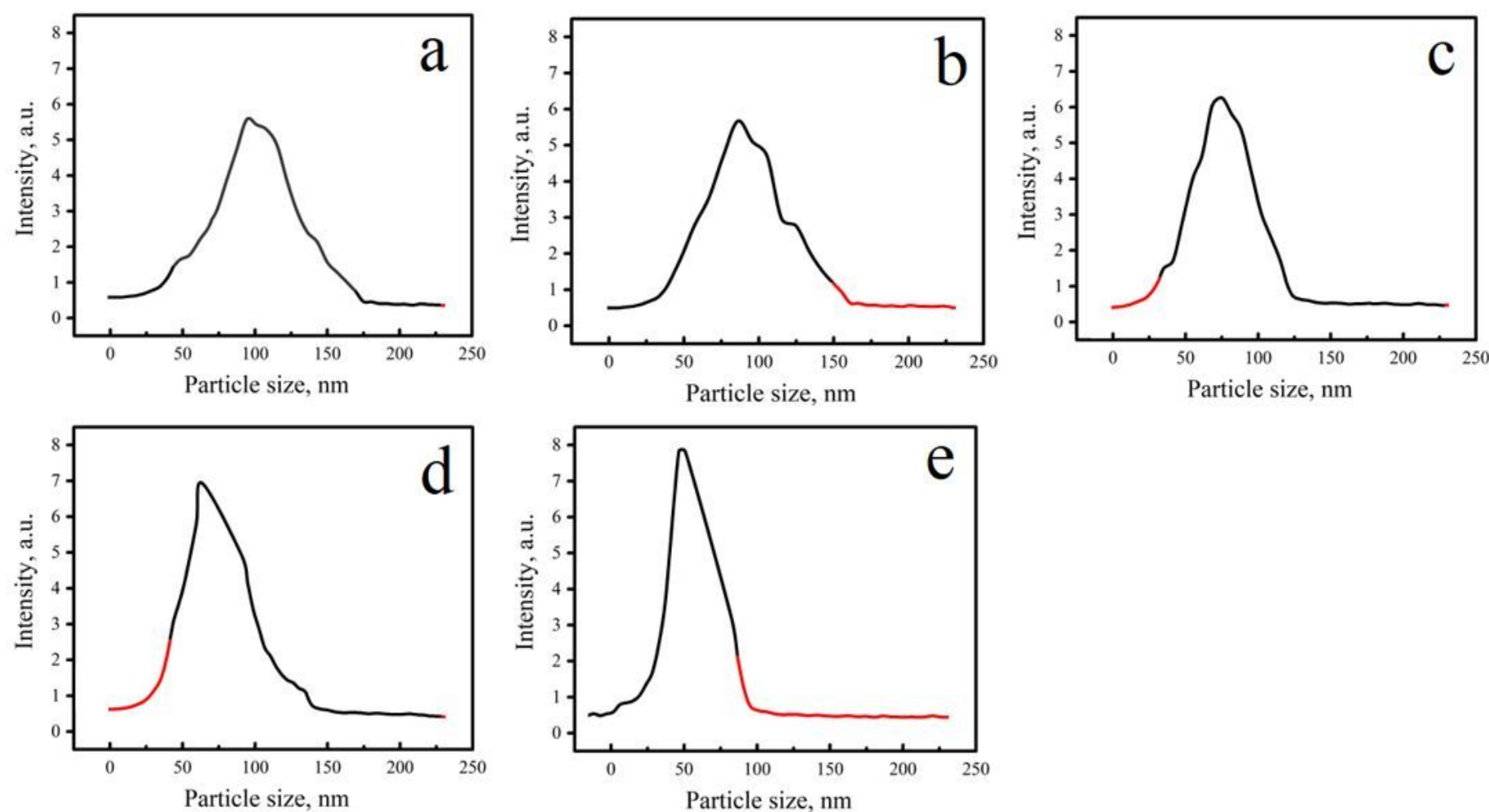

\section{Figure 3}

Particle size distribution of milled powders at various ZrO2 content
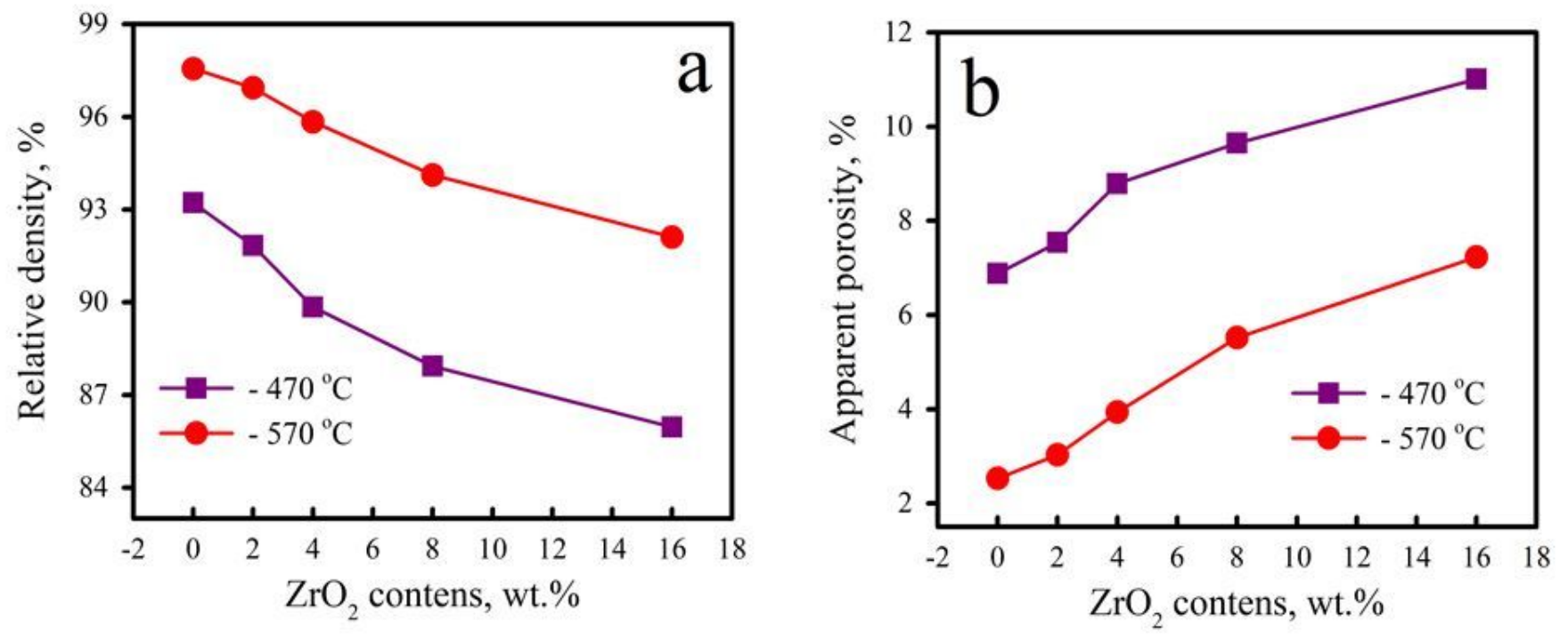

Figure 4

(a) Relative density and (b) apparent porosity of the prepared nanocomposites samples sintered 

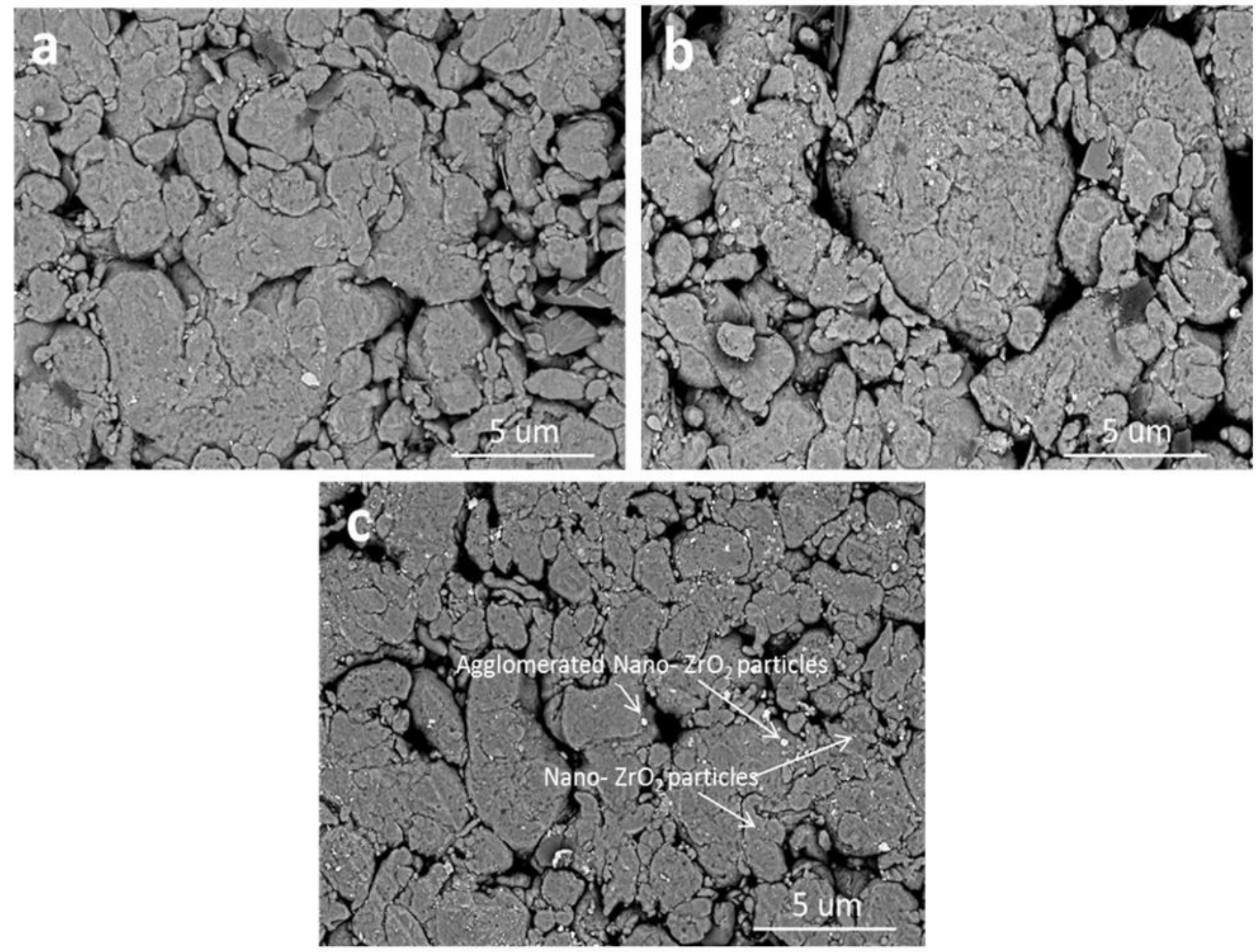

Figure 5

SEM images of a) AZO, b) AZ4 and c) AZ16 compacted samples. 

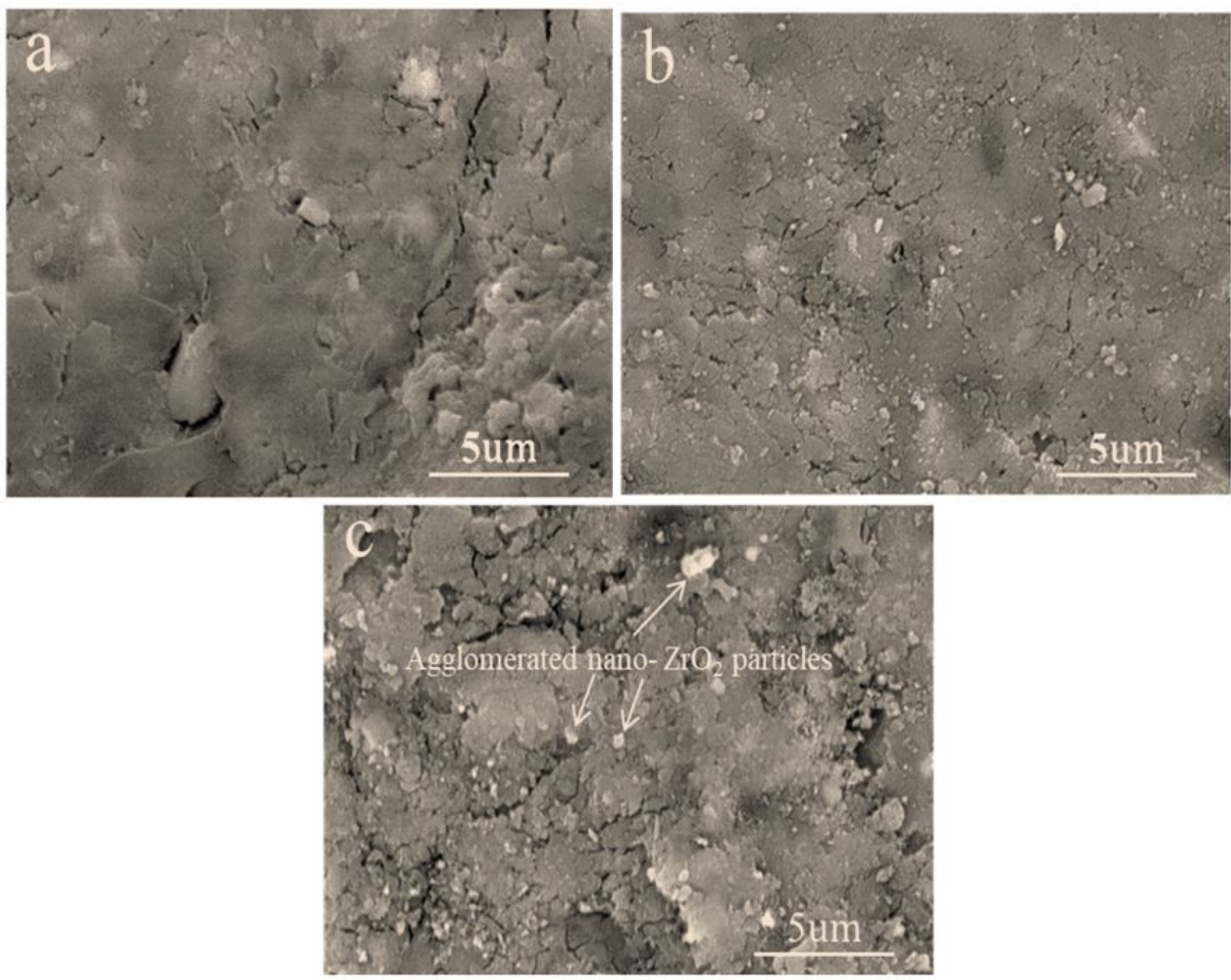

Figure 6

SEM micrographs of a) AZ0, b) AZ4 and c) AZ16 samples sintered at $470{ }^{\circ} \mathrm{C}$. 

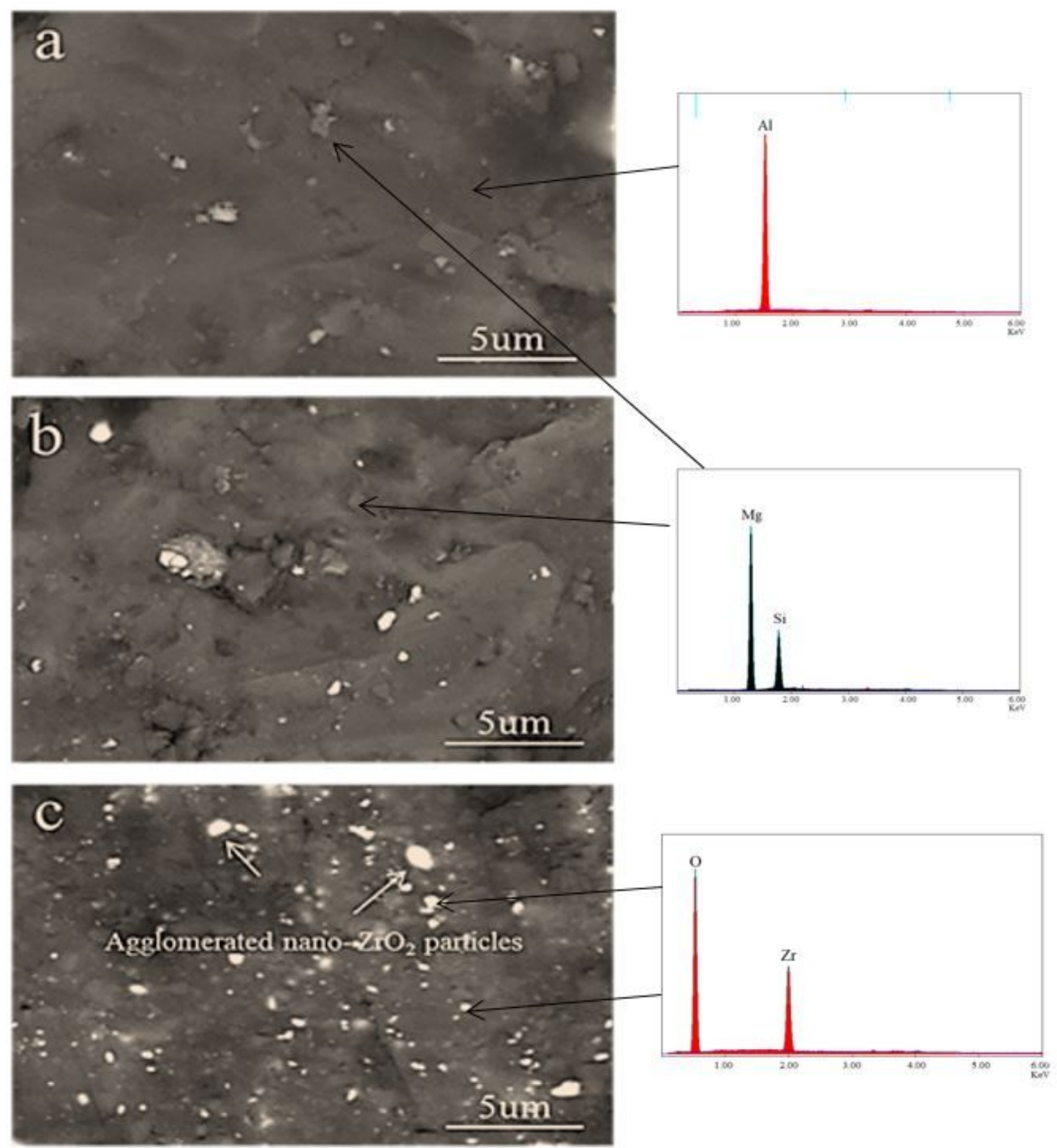

Figure 7

SEM micrographs of a) AZO, b) AZ4 and c) AZ16 samples sintered at $570{ }^{\circ} \mathrm{C}$ along with their corresponding EDS patterns. 


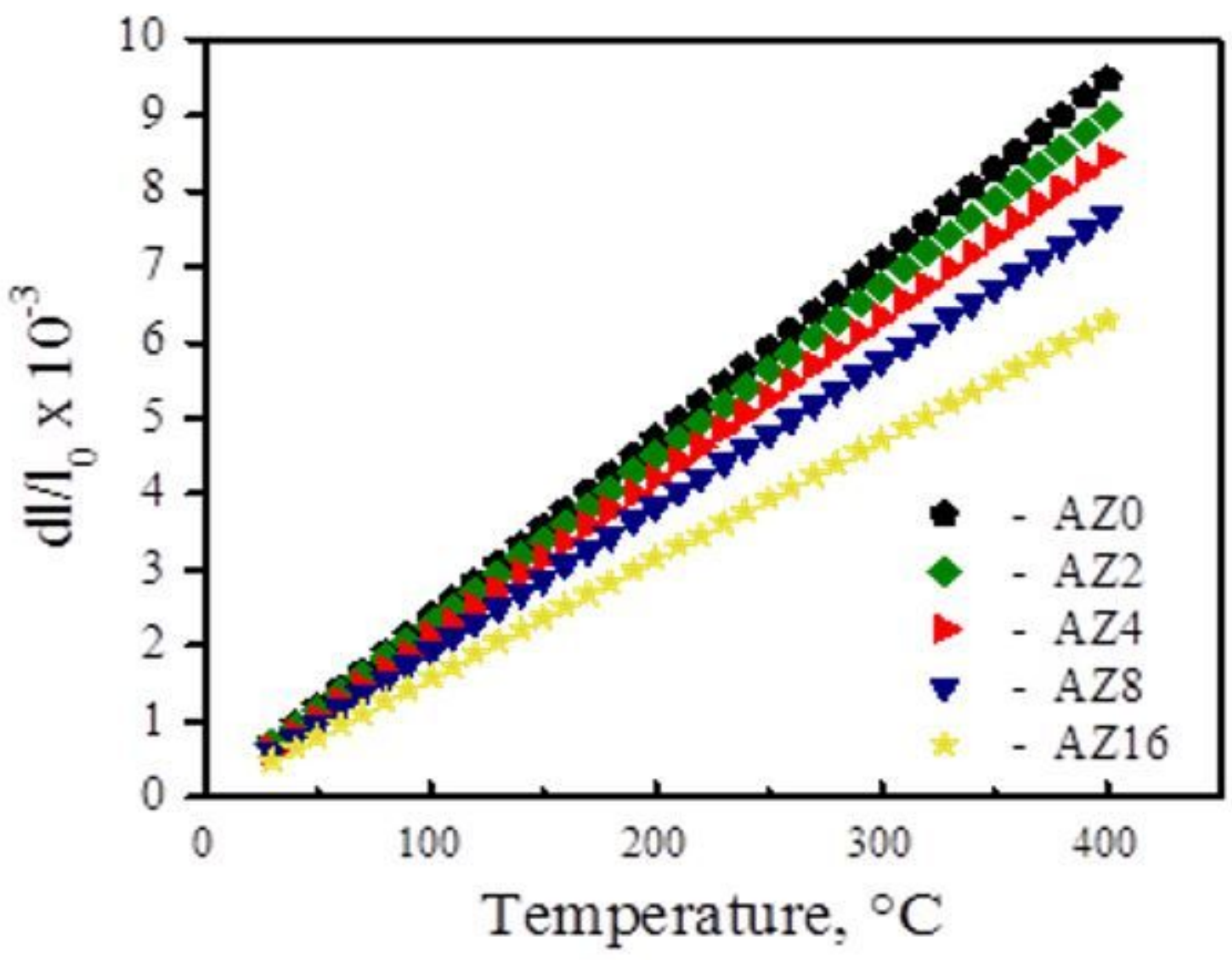

Figure 8

Thermal expansion behavior of samples versus ZrO2 contents. 


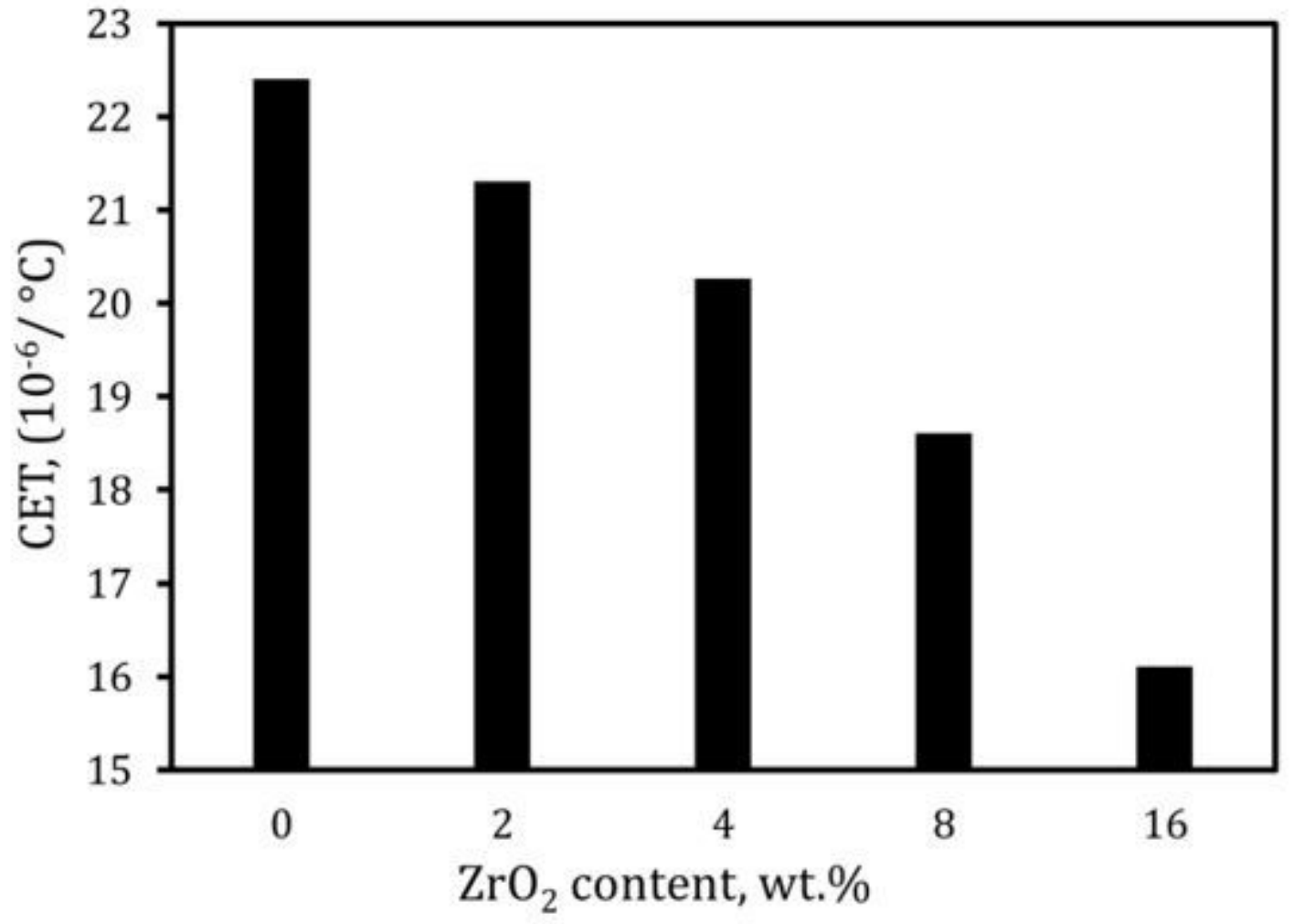

Figure 9

The changes in CTE values versus ZrO2 contents of the sintered nanocomposites. 


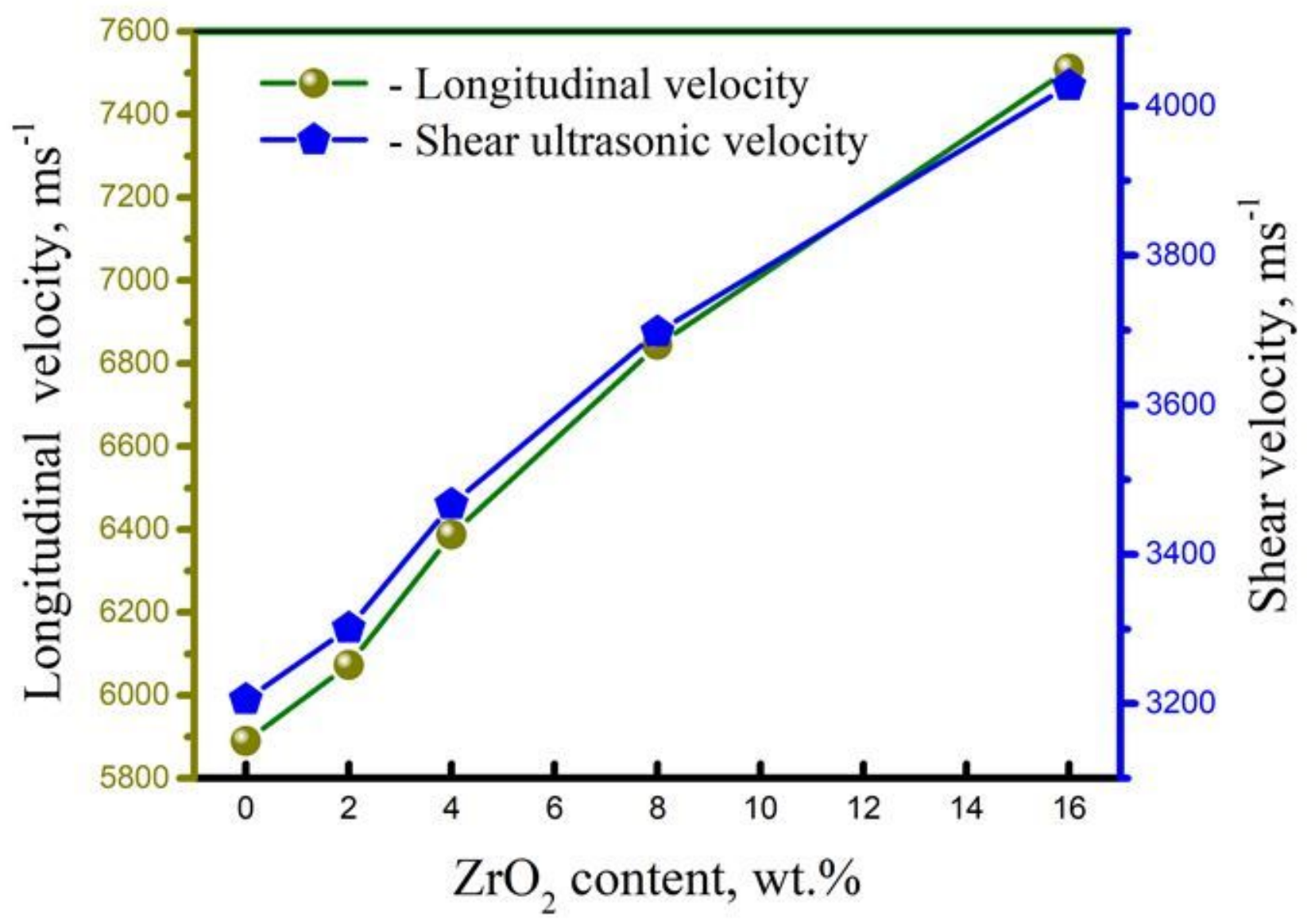

Figure 10

Ultrasonic velocities of nanocomposites samples sintered at $570{ }^{\circ} \mathrm{C}$ versus different $\mathrm{ZrO} 2$ contents. 

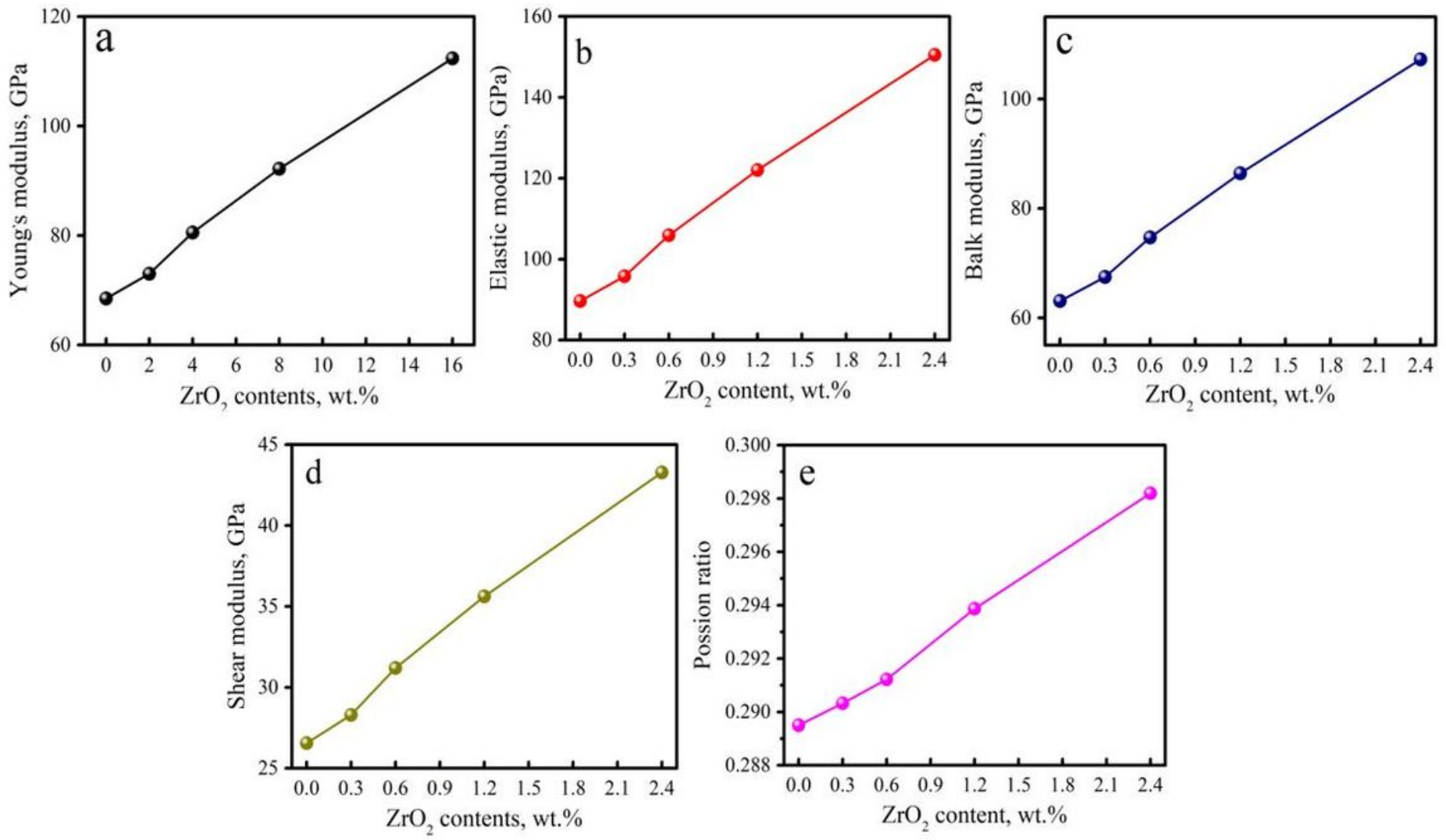

Figure 11

The group of elastic moduli of nanocomposites samples sintered at $570{ }^{\circ} \mathrm{C}$ versus different $\mathrm{ZrO} 2$ contents. 


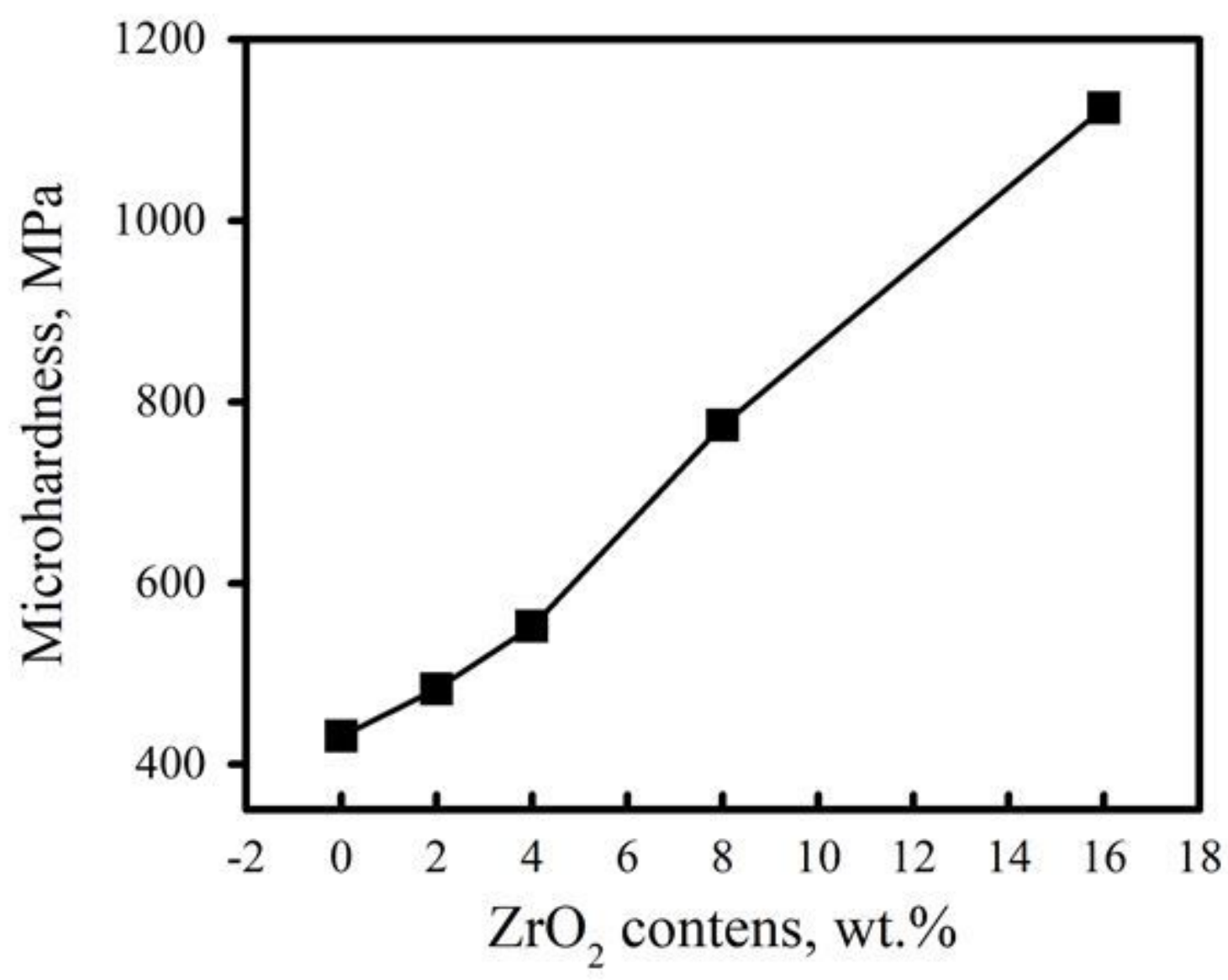

Figure 12

Microhardness of nanocomposites samples sintered at $570{ }^{\circ} \mathrm{C}$ versus $\mathrm{ZrO} 2$ contents. 


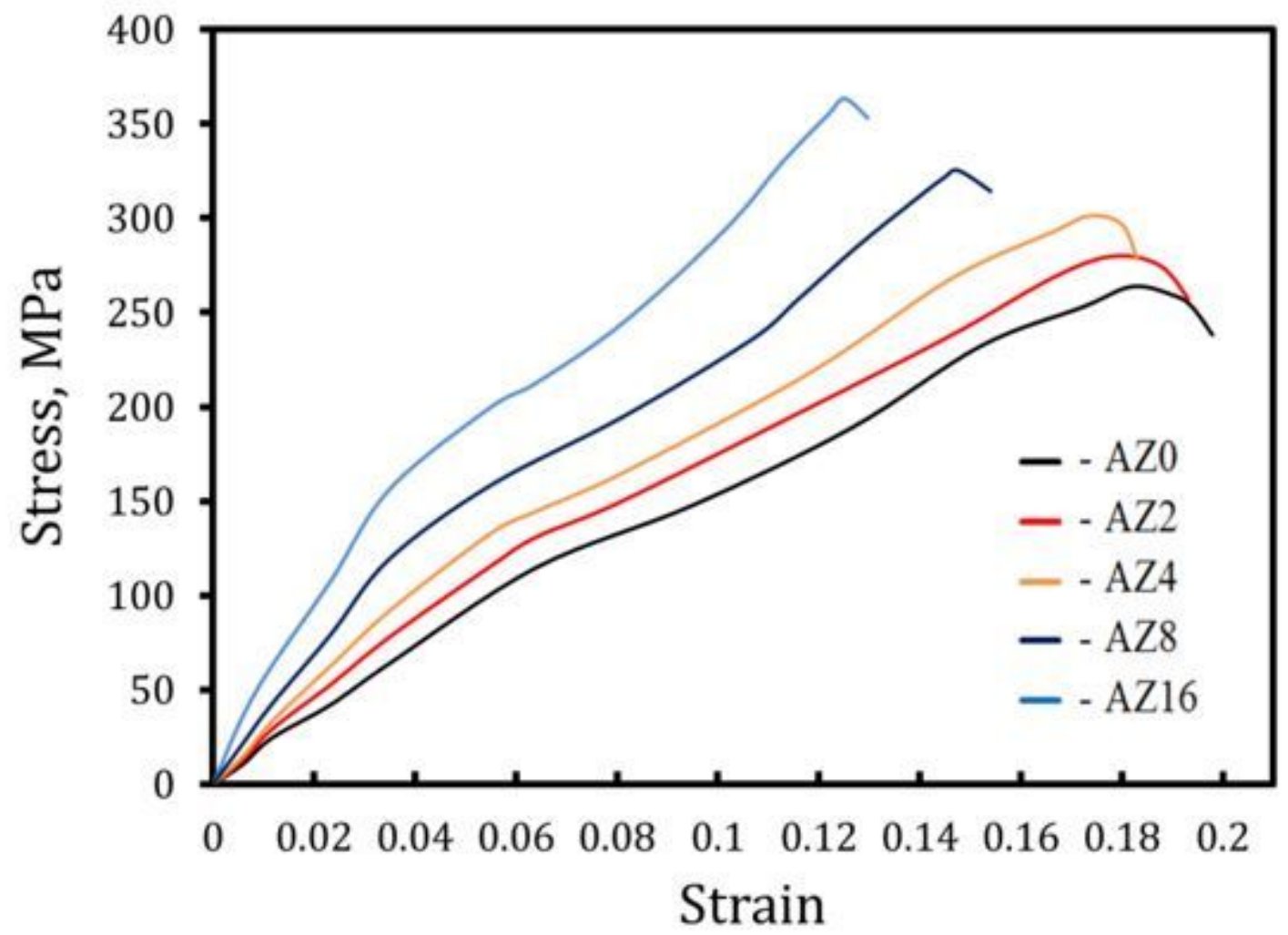

Figure 13

Compressive stress versus strain curve of Al alloy-ZrO2 samples sintered at $570{ }^{\circ} \mathrm{C}$.
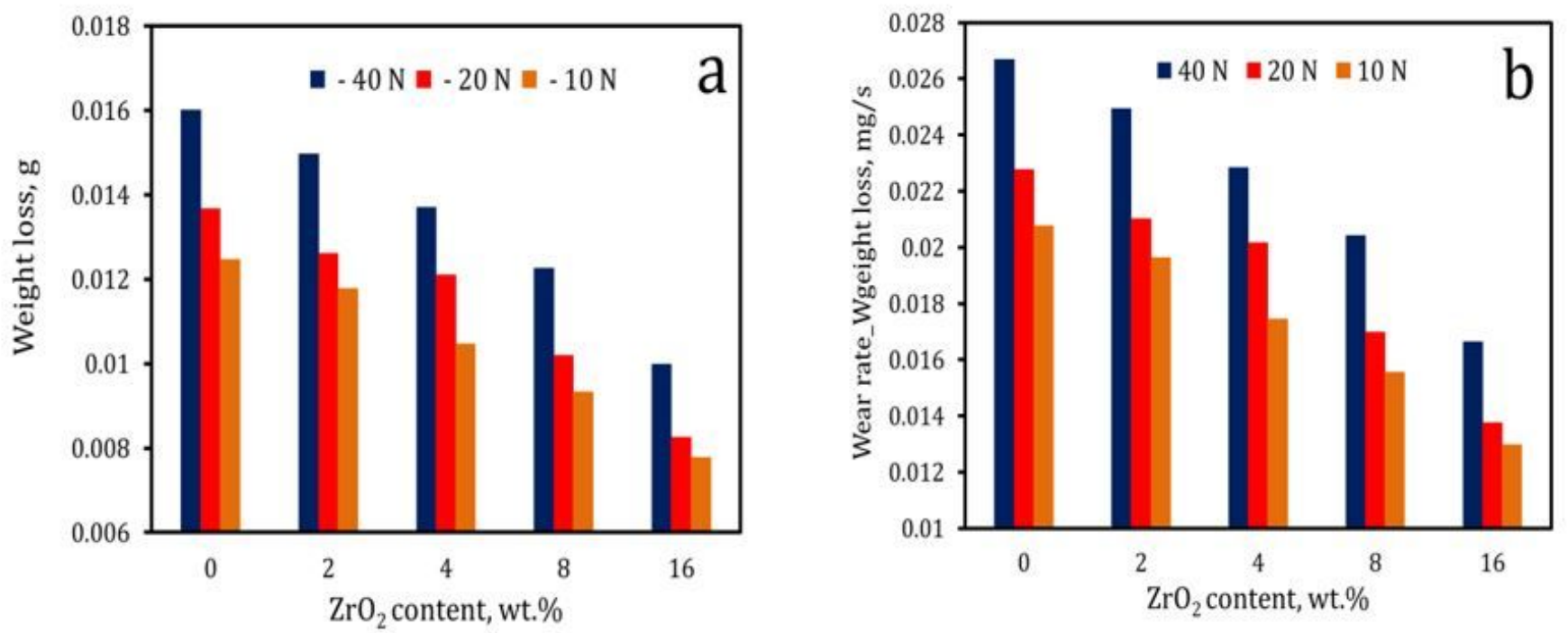

Figure 14

a) Weight loss and b) wear rate of specimens sintered at $570{ }^{\circ} \mathrm{C}$ for different applied loads. 

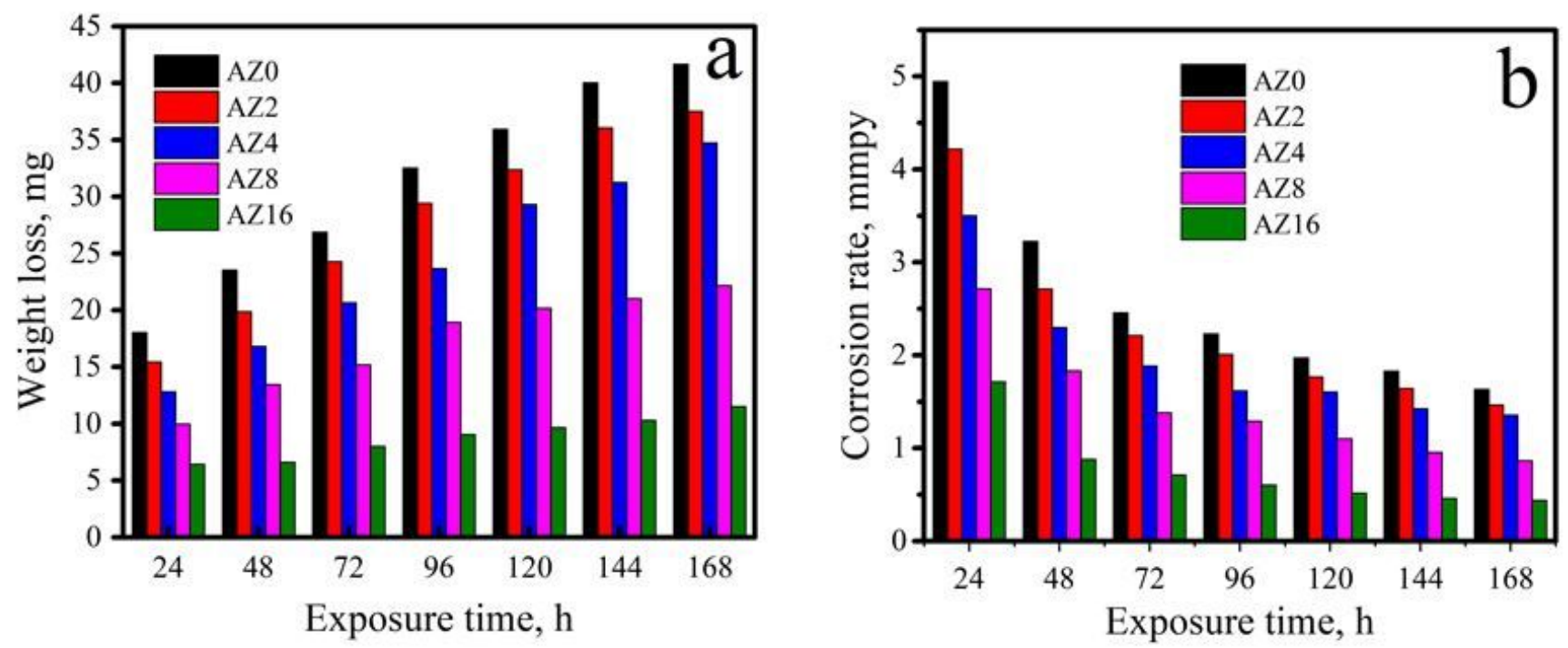

Figure 15

a) Weight loss and b) corrosion rate of specimens sintered at $570{ }^{\circ} \mathrm{C}$ for different applied loads. 